\title{
FRIEDRICH HAYEK Y SUS DOS VISITAS A CHILE*
}

\author{
Bruce Caldwell \\ Duke University \\ Leonidas Montes \\ Universidad Adolfo Ibáñez
}

Bruce Caldwell (EE.UU., 1952). Economista y PhD en economía en la Universidad de North Carolina en Chapel Hill. Profesor e investigador del Departamento de Economía en Duke University y director del Center for the History of Political Economy. Email: bruce.caldwell@duke.edu

Leonidas Montes (Santiago, 1966). Ingeniero civil industrial, licenciado en filosofía y magíster en ciencia política por la Pontificia Universidad Católica de Chile. $\mathrm{PhD}$ y MPhil en economía en la Universidad de Cambridge (King's College). Entre 2009 y 2014 fue decano de la Escuela de Gobierno de la Universidad Adolfo Ibáñez (UAI), donde hoy es académico. Email: leonidas.montes@uai.cl

* Para los propósitos de full disclosure, Bruce Caldwell es editor general de The Collected Works of F. A. Hayek, y ha sido miembro de la Mont Pèlerin Society desde 2010. Y Leonidas Montes ha sido miembro del consejo directivo y del comité ejecutivo del Centro de Estudios Públicos (CEP) desde 2005. Este artículo es una versión adaptada y más breve de un trabajo publicado por Caldwell y Montes en inglés (ver sección "Referencias"). Los autores agradecen tanto el apoyo de Universidad Adolfo Ibáñez como el del Center for the History of Political Economy, del Departamento de Economía de la Universidad de Duke, para realizar esta investigación. También agradecen los comentarios de Robert Barros, Javier Couso, Renato Cristi, Andrew Farrant e Iván Jaksic, las entrevistas de Carlos Cáceres y Jorge Cauas, la autorización para reproducir extractos de los archivos de Friedrich Hayek, así como el acceso a los archivos de Pedro Ibáñez Ojeda, permitida por Adolfo Ibáñez Santa María. 
Resumen: F. A. Hayek visitó Chile en dos ocasiones, en 1977 y 1981. Ambas visitas fueron polémicas. En su primer viaje se reunió con Pinochet. Esto dio pie para que se especulara en torno a su influencia en la Constitución de 1980. Después de cada visita Hayek se quejó porque la prensa extranjera no entregaba una imagen justa de la situación económica. Este artículo, basado en archivos, periódicos, revistas, entrevistas y publicaciones recientes, da cuenta de las circunstancias y los detalles de ambas visitas de Hayek a Chile y su influencia.

Palabras clave: F. A. Hayek, Milton Friedman, Escuela de Chicago, Augusto Pinochet, régimen militar, Constitución de 1980, Centro de Estudios Públicos.

RECIBIDO: octubre 2014; ACEPTADO: diciembre 2014.

\section{FRIEDRICH HAYEK AND HIS TWO VISITS TO CHILE}

Abstract: F. A. Hayek visited Chile twice, in 1977 and 1981. Both visits were polemical. On the first trip he met with Augusto Pinochet. This led to some speculations about his influence on the Constitution of 1980. After each visit, Hayek complained that the western press did not provide a fair picture of the economic situation. Drawing on archival material, newspapers, magazines, interviews, and recent research, this essay provides a full account of the circumstances and details of Hayek's visits to Chile and his influence.

Keywords: F. A. Hayek, Milton Friedman, Chicago Boys, Augusto Pinochet, military regimen, Constitution of 1980, Centro de Estudios Públicos.

ReCEIVED: October 2014; ACCEPTED: December 2014.

D os libros recientes, de Stedman Jones (2012) y Burgin (2012), han desarrollado y analizado la influencia del neoliberalismo desde una perspectiva histórica e intelectual, destacando el rol protagónico que jugaron Milton Friedman y Friedrich A. Hayek. Y aunque resulta difícil definir lo que realmente queremos decir cuando hablamos de neoliberalismo (ver MacEwan 1999; Harvey 2005; Mirowski 2009, 417-55; Caldwell 2011, 301-34), la influencia de Hayek y Friedman es innegable, y su impacto, evidente. De hecho, durante el siglo XX su importancia es sólo comparable a la que tuvo John Maynard Keynes.

La visita de Milton Friedman a Chile en 1975 fue motivo de duras críticas y existe bastante literatura al respecto. En cambio, los dos via- 
jes de Hayek a Chile, en noviembre de 1977 y abril de 1981, sólo han generado cierto interés reciente, dando origen a algunas publicaciones. Este ensayo investiga la historia de ambas visitas y cuestiona algunas interpretaciones que se han tejido en torno a éstas.

La primera sección se inicia con algunas circunstancias de la vida de Friedrich Hayek antes de su primer viaje a Chile. En seguida se investiga su visita a Chile en noviembre de 1977, invitado por la Universidad Técnica Federico Santa María para recibir el grado de Doctor Honoris Causa. La sección tres analiza críticamente algunas interpretaciones, argumentando que durante los años setenta el pensamiento de Hayek, más allá de su popular The Road to Serfdom (1945), era prácticamente desconocido en Chile. La sección cuatro analiza su segunda visita en abril de 1981, esta vez invitado como presidente honorario del Centro de Estudios Públicos (CEP). En esta sección se argumenta que sólo entonces sus ideas comenzaron a difundirse. Además, se analizan algunas diferencias que surgieron en los inicios del CEP entre los Chicago Boys y aquellos que proponían una mirada más hayekiana. El ensayo finaliza con algunas breves conclusiones.

\section{HAYEK EN LA DÉCADA DE LOS SETENTA}

En 1969, Friedrich Hayek y su segunda mujer, Helen Bitterlich, se trasladaron de la Universidad de Friburgo en Alemania Occidental, a la Universidad de Salzburg en Austria. No fue una buena decisión. Por una serie de razones, Hayek no estaba contento. Su estado de ánimo afectó su trabajo intelectual. Incluso se ha sugerido que sufrió una depresión (Kresge y Wenar 1994, 130-1). Pero a comienzos de 1974 salió de su depresión y volvió a trabajar con la intensidad de siempre. Ya recuperado e intelectualmente activo, en octubre de ese mismo año se anuncia que recibiría el Premio Nobel junto al economista sueco Gunnar Myrdal. Con este nuevo impulso, en los próximos años terminaría su trilogía Law, Legislation and Liberty (Hayek 1973, 1976, 1979) abriendo, además, una nueva línea de investigación con la publicación de su ensayo The Denationalization of Money (Hayek 1978).

El Premio Nobel lo convirtió nuevamente en una figura intelectual pública. Esa experiencia ya la había vivido en su tour por los Estados Unidos cuando la famosa e influyente revista Reader's Digest había pu- 
blicado un resumen de su edición de The Road to Serfdom. El éxito de su libro, estimulado por la amplia difusión a través de Reader's Digest, lo convirtió en una figura conocida para millones de lectores (ver Hayek [1944] 2007, 18-22). En ese entonces sus ideas liberales recibieron mucha atención mediática. Casi treinta años después, con el Premio Nobel de 1974, esta historia se repetía. Los sombríos y poco productivos años en Austria quedaron atrás. Nuevamente Hayek estaba dando entrevistas para diarios, revistas, radio y televisión. Era invitado a dar clases inaugurales y lectures a distintas universidades. Visitaba diversos países, conocía a políticos, hombres de negocios y autoridades de gobierno. Como sus ideas económicas y políticas eran poco conocidas en los setenta, tenían la virtud de ser novedosas y originales. Una serie de artículos que explicaban $-\mathrm{y}$ con mayor frecuencia criticaban — su pensamiento aparecían con cierta regularidad en la prensa. El mismo Hayek participaba activamente del debate, escribiendo regularmente cartas a The Times de Londres y Frankfurter Allgemeine Zeitung (FAZ) en Alemania.

A fines de marzo de 1975, sólo dos meses después de que Hayek recibiera el Premio Nobel en Suecia, Milton Friedman acompañó, junto a su mujer Rose, a su colega de la Universidad de Chicago Arnold C. Harberger ("Al" para los americanos y "Alito" para los chilenos), en un viaje a Chile donde daría una serie de charlas y seminarios en economía. ${ }^{1}$ En los seis días que duró dicha visita, Friedman participaría en una serie de seminarios y clases (Friedman y Friedman 1998, 398-9). De hecho, dio dos charlas sobre política monetaria, una en la Escuela de Negocios de Valparaíso y otra —el objeto principal de su visita — para la Fundación de Estudios Económicos. ${ }^{2}$ Pero además dio dos charlas acerca de "La fragilidad de la libertad", en la Universidad de Chile y en la Pontificia Universidad Católica de Chile, donde usó a Chile como un

${ }^{1}$ La invitación provino de la Fundación de Estudios Económicos dependiente del Banco Hipotecario de Chile, controlado por Javier Vial, cuyo grupo económico - Grupo Vial- colapsaría en la crisis financiera y económica de 1982. También los acompañaba Carlos G. Langoni, que se había graduado como $\mathrm{PhD}$ en economía de Chicago en 1970 con su tesis "A Study in Economic Growth: The Brazilian Case". Langoni entonces sólo tenía 30 años y era sub-director de la Escuela de Postgraduados en Economía de la Fundación Getulio Vargas en Brasil. Entre 1980 y 1983 Langoni sería presidente del Banco Central de Brasil.

${ }^{2}$ La charla para Fundación de Estudios Económicos, junto a las preguntas y respuestas, se encuentra íntegramente publicada en Friedman et al. (2012, 17-62) 
ejemplo de esta fragilidad. ${ }^{3}$ El Mercurio sólo menciona escuetamente la charla que daría Milton Friedman en la Universidad de Chile ( $E l$ Mercurio, 26 de marzo, 1975). Y La Segunda se refiere a la charla que dio en la Pontificia Universidad Católica de Chile, destacando que "se refirió a la condición que impone la libertad económica sobre la libertad política" (La Segunda, 26 de marzo, 1975). Lo que dijo en ambas universidades es consistente con su postura intelectual de que un sistema de libertad económica es condición necesaria para la libertad política (ver, por ejemplo, Friedman 1962). ${ }^{4}$

En su visita a Chile, Milton Friedman, junto a Harberger y Langoni, se reunieron con Augusto Pinochet durante 45 minutos (Friedman y Friedman 1998, 399). ${ }^{5} \mathrm{Si}$ bien la inflación había retrocedido respecto al peak que alcanzó en 1973 , ésta seguía siendo muy elevada $(606,1$ por ciento en 1973; 369,2 por ciento en 1974; 343,3 por ciento en 1975). Friedman le recomendó a Pinochet una disminución drástica de la oferta de dinero para controlar la inflación. En seguida le envió una carta con ésta y otras recomendaciones (Friedman y Friedman 1998, 399; la carta está en 5914). Aunque generalmente se ha asumido que el llamado shock therapy o shock treatment plan sería consecuencia de la visita de Friedman a Chile, lo cierto es que dicho plan —el "Programa de recuperación económica" ya había sido diseñado antes por Jorge Cauas y algunos Chicago Boys. ${ }^{6}$

${ }^{3}$ Milton Friedman recuerda que después dio esencialmente la misma charla bajo el título "The Fragility of Freedom" en Brigham Young University, en diciembre de 1975, y publicó una versión revisada como "The Line We Dare Not Cross" en Encounter, noviembre de 1976 (8-14). Otra versión también fue publicada como “The Path We Dare Not Take" en Reader's Digest, en marzo de 1977 (110-15) (Friedman y Friedman 1998, 631, nota 7). Para las charlas ver Friedman 1976a y 1977. Cabe notar que también dio esta charla en la Universidad de Cape Town, el 22 de marzo de 1976 (Friedman 1976b, 3-10).

${ }^{4}$ La Segunda también reporta que en la Pontificia Universidad Católica de Chile respondió preguntas del público. Friedman recordaría más tarde que “... al escuchar dicha charla había una actitud de shock que permeaba a ambos grupos de estudiantes" (Friedman y Friedman 1998, 400). Más aún, Friedman no quiso aceptar grados honorarios de ninguna de estas universidades (Friedman y Friedman 1998, 598).

5 "La reunión [con Pinochet] se prolongó desde las 17:30 hasta las 18:15 aproximadamente" (El Mercurio, 22 de marzo, 1975).

${ }^{6}$ Basta leer la carta de respuesta de Pinochet a Milton Friedman del 16 mayo de 1975, donde agradece sus consejos, agregando que "en gran parte coinciden con el 'Programa de recuperación económica' propuesto por el ministro Jorge Cauas" (Friedman y Friedman 1998). Para una interesante y entretenida historia de los Chicago Boys en Chile, ver Valdés (1995). 
A comienzos de octubre de ese año, el viaje de Friedman a Chile fue criticado por el columnista Anthony Lewis en The New York Times ("For Which We Stand: II", 2 de octubre, 1975). En seguida comenzaron las protestas de estudiantes en la Universidad de Chicago. Estas protestas, que incluyeron manifestaciones en el edificio del departamento donde Friedman vivía con su mujer, "fueron las primeras de muchas que seguirían en los próximos cinco años" (Friedman y Friedman 1998, 402). Las manifestaciones, artículos y columnas continuaron apareciendo con cierta frecuencia e intensidad.

Pero al año siguiente las cosas empeoraron. Orlando Letelier había escrito una columna en The Nation en la que criticaba a Friedman y a los Chicago Boys por aconsejar a Pinochet la imposición del "Programa de recuperación económica" (The Nation, 28 de agosto de 1976, 13742). ${ }^{7}$ Sólo tres semanas después, el 21 de septiembre de 1976, Orlando Letelier sería brutalmente asesinado en Washington, donde también murió Ronni Moffitt, su colega y ciudadana estadounidense. En este contexto, el ensayo de Letelier, "The 'Chicago Boys' in Chile: Economics 'Freedom's' Awful Toll” (Letelier 1976), que acusaba a Friedman de ser "el arquitecto intelectual y asesor no oficial del grupo de economistas que manejan la economía chilena" (137), sería citado y reproducido en diversas publicaciones.

El 14 de octubre de 1976, tan sólo tres semanas después del impactante asesinato de Letelier, se anunció que Friedman recibiría el Premio Nobel de Economía. Diez días después, The New York Times publicó una carta de dos Premio Nobel, George Wald (Medicina) y Linus Pauling (Química y Paz), en la que criticaban al comité de premiación por "una deplorable exhibición de insensibilidad" al otorgarle el premio a Friedman. Otra carta, ese mismo día, firmada por David Baltimore y

${ }^{7}$ Letelier reacciona ante una respuesta de Friedman a una carta al Newsweek, donde un Comité de DD.HH. lo critica por aconsejar a la junta militar chilena en materias económicas (Newsweek, 14 de junio de 1976). En su respuesta, Friedman manifiesta su profundo desacuerdo con el gobierno autoritario chileno, pero no considera una "maldad" que un economista aconseje técnicamente a un gobierno, así como lo podría hacer un médico ante una enfermedad. Este mismo argumento ya lo había esgrimido en otras ocasiones (ver, por ejemplo, Friedman y Friedman 1998, 595-6). Por otra parte, para recalcar la imagen de Friedman como el "arquitecto intelectual y asesor no oficial" del régimen militar, Orlando Letelier se refiere a la primera visita de Friedman en 1975 como "la última visita conocida de Friedman y Harberger a Chile” (Letelier 1976, 137 y 140; ver también Hammond 2003, 142). 
Salvador Edward Luria (ambos Premio Nobel de Medicina), calificaba la decisión del comité como "perturbadora" y "un insulto para la gente de Chile que cargaba con las reaccionarias medidas económicas avaladas por el profesor Friedman" (Friedman y Friedman 1998, 596-7). ${ }^{8}$

En diciembre, cuando Friedman viaja a Suecia para recibir el premio, se produjeron múltiples y masivas manifestaciones. En la ceremonia misma de la entrega del Premio Nobel, cuando Friedman iba a recibirlo, un manifestante gritó: "Abajo el capitalismo, libertad para Chile”. Las protestas perseguirían a Friedman por años. Por esta razón, con su habitual agudeza y franqueza, Milton Friedman se quejaría: nunca sabría si debía considerar "más divertida o más molesta la acusación de manejar la economía de Chile desde el escritorio de mi oficina en Chicago" (400).

Este episodio se relaciona con Hayek. El 14 de diciembre de 1976, cuatro días después de la ceremonia de entrega del Premio Nobel a Milton Friedman, Gunnar Myrdal publicó una larga columna en el diario sueco Dagens Nyheter, la que pronto aparecería reproducida en la popular revista americana Challenge. A causa del Premio Nobel dado a Friedman, Myrdal critica a la Academia Sueca de las Ciencias por sus prácticas secretas en la elección de los premiados. También argumenta que la entrega del Premio Nobel de Economía - una ciencia "blanda" - debería descontinuarse ya que es un acto político. En seguida discute el Nobel que compartió con Hayek —en su opinión, otro acto político-, destacando: "[Los] miles de cablegramas que recibí de colegas de todo el mundo, informándome que eran profundamente críticos de que el Premio Nobel le hubiera sido entregado a Hayek" (Myrdal 1977, 52). Termina su ensayo expresando su arrepentimiento por haber recibido el Premio Nobel. Su excusa es: "Debería haberme negado a aceptarlo, particularmente no necesitaba el dinero y lo doné [...]. Pero entonces no había pensado el problema en profundidad. Estaba solamente disgustado. Además, el mensaje me llegó muy temprano en la mañana en Nueva York, cuando estaba completamente fuera de guardia" (52).

${ }^{8}$ Si bien las cartas fueron publicadas el 24 de octubre de 1976 en The New York Times, ambas tenían fecha del 14 de octubre, el mismo día en que se anunció el Premio Nobel de Economía para Milton Friedman. 
Todo este debate era de público conocimiento. El 31 de mayo de 1977, The New York Times publica un artículo de Leonard Silk en el que relata las críticas sobre el Premio Nobel de Economía a Friedman, refiriéndose al ensayo de Myrdal como "un bombazo que ha seguido a esta tormenta".

Hayek supo del ensayo de Myrdal antes de que apareciera su traducción al inglés. ${ }^{9}$ Durante toda su carrera académica, Hayek había sido reconocido por mantener las diferencias con sus adversarios a un nivel profesional y respetuoso. ${ }^{10}$ Ciertamente este episodio era, a lo menos, incómodo. El tratamiento que estaba recibiendo Friedman le tiene que haber molestado a Hayek, quizá tanto o más que los destemplados comentarios publicados por Myrdal.

También sabemos que en ese período Hayek estaba muy inquieto con el rumbo que tomaba la economía como profesión. De hecho, entonces pensaba escribir un libro titulado What is Wrong with Economics ("Qué está mal con la economía"). No llevó a cabo esta empresa, pero en los setenta dedicó mucho tiempo al "Paris Challenge", un debate que esperaba organizar para contrastar el capitalismo contra el socialismo. Este proyecto tampoco se materializó, pero todo esto sirvió de base y fundamento para escribir The Fatal Conceit: The Errors of Socialism (1988), su última publicación importante.

Es precisamente en este contexto, y en medio de la Guerra Fría, cuando en mayo de 1977 Hayek recibe una invitación para visitar Chile. Ésta fue enviada a Friburgo y reenviada a The Hoover Institution, en la Universidad de Stanford, donde Hayek pasaba ese mes de verano. En ese entonces, Milton Friedman, quien recién el año anterior se había retirado —o, mejor dicho, jubilado a los 65 años como profesor de Chicago (Friedman y Friedman 1998, 559)-, era un senior fellow de The Hoover Institution en Stanford y vivía con su mujer, Rose, en San Francisco. Indudablemente se tienen que haber visto y conversado. Lo más probable es que hayan hablado acerca de la visita de Friedman a Chile en 1975 y sus efectos. También de la situación económica de Chile durante el gobierno de la Unidad Popular y algunas de las reformas

${ }^{9}$ Ole-Jacob Hoff envió una carta a Friedman, con copia a Hayek, resumiendo el ensayo (ver Hayek Collection, box 147, en la colección de los archivos de Hayek que se encuentra en The Hoover Institution, en la Universidad de Stanford).

${ }^{10}$ Schumpeter $(1946,269)$ en su reseña a The Road to Serfdom caracteriza a este texto como "un libro respetuoso que no asigna a sus oponentes nada más allá del error intelectual. De hecho, el autor es respetuoso demás...". 
que se estaban realizando después del golpe militar. Quizá la reciente invitación a Hayek también pudo ser tema de conversación.

Hayek confiesa que una vez que aceptó la invitación a Chile recibió una serie de cartas y llamadas telefónicas: "Mucha gente bien intencionada que yo no conocía [...] todas intentaban convencerme de que no visitara un país tan objetado" (Hayek citado en Farrant et al. 2012, 518). Evidentemente el tema de los derechos humanos en Chile era la motivación de quienes le aconsejaban no viajar a Chile. ${ }^{11}$ Pero había otros factores en juego. El mundo estaba en medio de la Guerra Fría y Chile era censurado por haber derrocado por la fuerza a un gobierno marxista democráticamente electo. Hayek era un acérrimo crítico del socialismo y sin lugar a dudas debe haber sentido curiosidad por conocer un país que había transitado, mediante un golpe militar, de un gobierno marxista a un régimen militar autoritario que estaba promoviendo la liberalización económica a través de políticas de libre mercado. Considerando su carácter, lo que Hayek estaba viviendo y el contexto político de la Guerra Fría, no debería sorprendernos de que haya aceptado la invitación a Chile. ${ }^{12}$

\section{HAYEK VISITA CHILE EN NOVIEMBRE DE 1977}

\subsection{La visita}

Juan Naylor, rector de la Universidad Técnica Federico Santa María, envió una carta oficial, con fecha 12 de mayo de 1977, invitando a Hayek a dar una clase magistral y recibir un título honorífico. La

${ }^{11}$ Por ejemplo, Ralph Raico, estudiante de doctorado de Hayek en Chicago, el 13 de junio de 1977 le escribió una carta personal, advirtiéndole acerca de los abusos de los DD.HH. en Chile (Farrant y McPhail (2014) mencionan que esta carta se encuentra en la Hayek Collection, box 14, folder 20). Los reportes de la Comisión de las Naciones Unidas sobre los abusos de DD.HH. en Chile aparecieron en 1975 y 1976. Y también existían los informes de Amnesty International, a los que se refiere Raico en su carta.

${ }^{12}$ Charlotte E. Cubbit, secretaria de Hayek, recuerda en sus memorias: "Su visita a Chile fue, desde un comienzo, un asunto controvertido. Muchas personas estaban descontentas con que fuera para allá, algunos de sus amigos le pedían evaluarlo, otros le enviaban cartas de protesta y advertencias acerca del eventual daño que esta visita podía tener en su reputación. Sin embargo, Hayek no era una persona que podía ser influenciada con palabras de precaución mientras estuviera convencido de la propiedad de su acción" (Cubbit 2006, 19). 
invitación formal agrega que "la Escuela de Negocios de Valparaíso, Fundación Adolfo Ibáñez, arreglará todos los detalles de su visita”. Esta invitación fue enviada nuevamente junto a una carta, fechada el 25 de mayo de 1977, de Pedro Ibáñez Ojeda, ex senador de la República y entonces presidente de la Fundación Adolfo Ibáñez, de la cual dependía la Escuela de Negocios de Valparaíso, que a su vez estaba "oficialmente asociada" con la Universidad Técnica Federico Santa María. En ella, Ibáñez dice:

\begin{abstract}
Estimamos que una visita de una semana puede permitirle tener cierto conocimiento de nuestro país y sus problemas, y podría permitir varias oportunidades para promover los conceptos económicos y políticos desarrollados por usted [...]. Puede estar seguro que nuestro mundo académico así como la opinión pública en nuestro país escucharán con profundo interés sus iluminadores puntos de vista. ${ }^{13}$
\end{abstract}

En su carta, Pedro Ibáñez le recuerda a Hayek que su amigo común, Manuel Ayau, ya le había advertido acerca de esta invitación. Ayau, un prominente y entusiasta promotor del liberalismo clásico en Latinoamérica, fundador y rector de la Universidad Francisco Marroquín, era además miembro y activo participante de la Mont Pèlerin Society desde 1965, convirtiéndose en su presidente durante el período 1979-80. En efecto, el 30 de marzo de 1977 Ayau le había escrito a Hayek contándole que recientemente había recibido la visita del "ex senador Pedro Ibáñez, miembro de nuestra Mont Pèlerin Society y fundador y actual presidente de la Fundación Adolfo Ibáñez". ${ }^{14}$ Agrega que la fundación, creada hace unos 25 años, tenía una escuela de economía y negocios "en la misma línea filosófica" de la Universidad Francisco Marroquín, "filosofía que el senador Ibáñez ha expresado en su carrera política en Chile". En seguida le dice que la Universidad Técnica Federico Santa María ha recibido una beca de la "Earhart Foundation (Ann Arbor)" para invitar a algún economista distinguido, por lo que desea "transmitir esta invitación formal para que vaya a Chile a recibir el gra-

${ }^{13}$ La correspondencia y el itinerario de esta visita se encuentran en Hayek Collection, box 54, folder 23 .

${ }^{14}$ Pedro Ibáñez Ojeda fue aceptado como miembro de la Mont Pèlerin Society en 1969. 
do honorífico de la Universidad Técnica Federico Santa María y dicte algunas clases magistrales en su país durante este año, o cuando sea conveniente para usted". Por último, Ayau le solicitó a Hayek "si podría considerar favorablemente dicha invitación" y, en ese caso, "lo haga saber para que ellos puedan proceder a enviarle una invitación formal. Ellos estarían muy honrados con su aceptación". ${ }^{15}$

La carta de Ayau cumplió su objetivo. El 6 de abril de 1977, Hayek le responde: "Hace mucho tiempo he deseado ver la costa oeste de Sudamérica que no conozco y estaría complacido de recibir una invitación de la Universidad Santa María [sic]". ${ }^{16}$ El 10 de junio Hayek le envía una carta manuscrita a Pedro Ibáñez en la que acepta la invitación y agrega que "en cuanto tenga acceso a una máquina de escribir, una vez que esté en The Hoover Institution, Stanford", le enviará una respuesta oficial, y que la carta manuscrita se debe a que "sólo quería enviarle de una vez esta respuesta". ${ }^{17}$ Finalmente, el 13 de junio de 1977, Hayek envía una confirmación formal desde The Hoover Institution aceptando la invitación.

Meses después, Hayek recibirá una carta de Carlos Cáceres, entonces decano de la Escuela de Negocios de Valparaíso (y más tarde presidente del Banco Central, ministro de Hacienda y ministro de Interior de Pinochet). En el intercambio afinaron detalles de la visita y a fines de octubre Cáceres le envío un itinerario preliminar para su visita a Chile. ${ }^{18}$

De acuerdo con ese itinerario, Hayek llegaría a Santiago el lunes 14 de noviembre, para viajar directamente a Viña del Mar. El martes 15 recibiría el Doctor Honoris Causa de la Universidad Técnica Federico Santa María y daría su charla magistral. Una conferencia de prensa estaba organizada para la tarde. El miércoles se reuniría con miembros de la Escuela de Negocios de Valparaíso y viajaría a Santiago en la tarde.

${ }^{15}$ Carta de Manuel Ayau a Hayek, 30 de marzo de 1977, Hayek Collection, box 54 , folder 21 .

${ }^{16}$ Carta de Hayek a Manuel Ayau, 6 de abril de 1977, archivos Pedro Ibáñez Ojeda.

${ }^{17}$ Carta de Hayek a Pedro Ibáñez, 10 de junio de 1977, archivos Pedro Ibáñez Ojeda.

${ }^{18}$ Después de su paso por Chile, el periplo también incluía visitas de casi una semana a Argentina, Brasil y Portugal, así como cuatro días en España (Hayek Collection, box 4, folder 29). 
El jueves en la mañana realizaría "visitas a las más altas autoridades de gobierno", almuerzo en El Mercurio, otra conferencia de prensa y un charla a estudiantes de la Escuela de Negocios de Valparaíso. El viernes se reuniría con miembros de diversas escuelas de economía y por la tarde daría una charla a hombres de negocios. Y para el sábado estaba organizada una visita a Colunquén, el campo de Pedro Ibáñez ubicado en el valle de Aconcagua. Finalmente el domingo viajaría a Buenos Aires, Argentina.

En la versión definitiva del itinerario aparecen nuevos eventos y algunas clarificaciones. Entre los primeros, "una visita al Presidente de la República" el jueves 17 de noviembre al mediodía, una entrevista con Qué Pasa a su llegada y otra con Ercilla el jueves a las 16:30. Finalmente una recepción en honor al político conservador alemán Franz Josef Strauss, fue agregada para el viernes. No sabemos si Hayek sabía con anticipación que iba a reunirse con Pinochet; no obstante, seis días antes de su llegada, el miércoles 9 de noviembre, El Mercurio informaba que el encuentro ya estaba planificado.

Carlos Cáceres y Pedro Ibáñez fueron las únicas personas que acompañaron a Hayek a su encuentro con Pinochet. Carlos Cáceres recuerda haber recogido a Hayek en el aeropuerto para llevarlo a Viña del Mar. En el camino pararon a comer una cazuela de ave en Casablanca y, una vez en el camino costero de Viña del Mar, pidió detenerse para investigar las formaciones rocosas. Cáceres recuerda poco de la reunión de Pinochet con Hayek, excepto que fue un encuentro breve, de unos veinte minutos, y que lo que se hubiera discutido, debido a los problemas de idioma (no había traductores), no había sido nada relevante. ${ }^{19}$ Es muy posible que Pinochet no haya sabido mucho de Hayek, excepto que era un Premio Nobel de Economía que apoyaba el programa de recuperación económica.

En los diarios de la época hay bastante información del encuentro con Pinochet, ya que habló con la prensa antes y después de la reunión. En El Mercurio se destaca en primera plana que Hayek "había conversado con el mandatario sobre el tema de la democracia limitada y el

${ }^{19}$ Entrevista de Bruce Caldwell y Leonidas Montes a Carlos Cáceres, 16 de noviembre, 2010. En un reciente testimonio, Carlos Cáceres recuerda lo mismo (Arancibia 2014, 38-9). 
gobierno representativo, sobre lo cual, según expuso, escribió un libro. Expuso que en ese trabajo señala que la democracia ilimitada no puede funcionar porque, en su opinión, crea una serie de fuerzas que después destruyen al régimen democrático. Señaló que el Jefe de Estado escuchó atentamente el tema y que le pidió le obsequiara los documentos que ha escrito sobre la materia" (El Mercurio, viernes 18 de noviembre, 1977). Esto es consistente con lo que recuerda su secretaria, Charlotte Cubbit, ya que a su regreso le solicitó que le enviara a Pinochet una copia del capítulo "A Model Constitution" de su obra Law, Legislation and Liberty. ${ }^{20}$ Considerando la relevancia del concepto de democracia limitada para Hayek, que Ibáñez y Cáceres eran miembros del Consejo de Estado y que en 1981 regiría una nueva constitución, es muy posible que Hayek se haya referido a sus propias ideas acerca de la constitución y la democracia. ${ }^{21}$

En el mismo artículo de El Mercurio, Hayek manifiesta su sorpresa por lo que ha visto en Chile: "Pensaba que Chile era un país subdesarrollado y ahora me doy cuenta de que no puedo usar ese término". Alaba al gobierno por las medidas económicas que está implementando y destaca que "observa una economía de mercado en la que quedan algunos resabios de estatismo que, en su opinión, serán superados". Consultado por el costo social de las medidas —el desempleo en 1976 y 1977 alcanzaba 21,9 y 18,1 por ciento, respectivamente_-, agrega: “Al haber un gobierno que está dispuesto a sacar adelante al país sin complejos, compromisos de popularidad o expectativas políticas, este costo es un mal necesario que rápidamente se va a superar”. Para Hayek, “el esfuerzo que está desplegando este país constituye un ejemplo a nivel mundial".

${ }^{20}$ Cubbit $(2006,19)$. Ella recuerda: "[Hayek] debe haber esperado influir en Pinochet, el dictador militar de Chile entre 1973 y 1990, porque lo visitó, le dio la mano y después me pidió que le enviara una copia de su último capítulo de Law, Legislation and Liberty III; esto es, 'A Model Constitution' junto con una carta". En la biblioteca personal de Pinochet, que está en la Academia de Guerra, sólo se encuentran copias de Camino de libertad: Friedrich A. Hayek (Centro de Estudios Públicos, 1981); ¿Inflación o desempleo? (Madrid: Unión Editorial S.A., 1976) y Los fundamentos de la libertad (Buenos Aires: Centro de Estudios de la Libertad, 4a edición, 1975).

${ }^{21}$ De acuerdo con La Segunda (18 de noviembre de 1977), en nota titulada "Reformas institucionales propone Premio Nobel Friedrich von Hayek", Hayek se refirió a algunas de sus ideas respecto de la constitución en una charla que diera en Valparaíso para la Corporación para el Desarrollo de la Empresa. 
Sus declaraciones iniciales fueron académicas y más bien cautas respecto de la situación en Chile. Pero se fue convenciendo de que en Chile se estaban haciendo las reformas de mercado que él valoraba. ${ }^{22}$

De hecho, en su primera entrevista para revista Qué Pasa, que de acuerdo con su itinerario fue dada a su llegada a Chile, al ser consultado por la política económica chilena, escueta y simplemente dice: "Considero que se está siguiendo el camino correcto". ${ }^{23}$ Respecto del uso del gasto público para generar empleo, dice que es "una práctica muy dañina, pero que desgraciadamente aparece como muy efectiva en el corto plazo. Aumenta el empleo, pero sólo se puede sostener mediante una inflación continuada y tal vez creciente. Los políticos la utilizan pensando en que: Apres nous, le deluge". Concluye con su idea de que "la democracia es un medio, no un fin; un método para una acción colectiva. El fin debe ser la libertad personal. Como un convenio que permite a la mayoría de los ciudadanos deshacerse en forma pacífica de un gobierno que no le gusta, es inestimable. Pero una democracia ilimitada es una de las peores formas de gobierno".

En cambio, en la entrevista que dio a revista Ercilla, días después, el jueves en la tarde, al ser consultado por la recuperación económica chilena, exclama: “ $i E s$ extraordinario! Estoy sorprendido. Nunca habría esperado encontrar este grado de prosperidad después de haber oído cómo estaba la economía hace tres años. Estoy completamente asombrado". ${ }^{24}$ No obstante, cuando le preguntan por una economía de libre mercado, donde Chile sólo tiene tasas de interés libre, pero salarios y tipo de cambio fijo, Hayek responde: “¿De veras? — pregunta asombrado- - Yo creía que tenían un tipo de cambio libre. Bueno, creo que esto no es muy dañino. El verdadero problema es la fijación de salarios y sueldos. Ninguna economía puede funcionar a no ser que los sueldos y salarios relativos estén equilibrados [...]. Si los salarios son

${ }^{22}$ Hay dos temas que pudieron llamar su atención. Una medida de impacto significativo y fundamental fue la renuncia de Chile, en julio de 1976, al Pacto Andino, un acuerdo comercial con Colombia, Perú, Bolivia, Venezuela y Ecuador, lo que permitió abrir la economía y fomentar las exportaciones (en 1979 Chile alcanzaría una tarifa de importaciones uniforme del 10 por ciento, excluyendo vehículos; ver testimonio de Sergio de Castro en Arancibia y Balart 2007, 253-7). El otro tema es que las medidas para combatir la hiperinflación comenzaban a ver la luz: durante 1977 ésta llegaría a 84,4 por ciento.

${ }^{23}$ Qué Pasa, 17 al 23 de noviembre de 1977.

${ }^{24}$ Ercilla, 23 de noviembre de 1977. 
inflexibles se transforman en el mayor obstáculo para el buen funcionamiento del mercado". Al margen de su acertado diagnóstico, resulta evidente que Hayek no estaba tan bien informado acerca de la economía chilena de ese entonces.

En resumen, Manuel Ayau, a quien Hayek conocía hace tiempo por la Mont Pèlerin Society, fue la pieza clave para su visita de 1977. Hayek se reunió con diversas autoridades de gobierno, con Pinochet, con empresarios y hombres de negocios, pero su visita tuvo un carácter principalmente académico. Aunque no existe evidencia para decir que Hayek haya sabido que se iba a reunir con Pinochet, era un hecho conocido en Chile. Evidentemente, desde la perspectiva de sus anfitriones, la visita de Hayek cumplió con el objetivo de legitimar las reformas económicas y el régimen militar. Si bien Hayek no estaba tan imbuido del estado de la economía chilena, en pocos días llegó a la conclusión de que la situación era mejor a lo que esperaba, y que la prensa internacional no daba cuenta de esta realidad.

\subsection{Algunas controversias}

El domingo 20 de noviembre Hayek viajó a Buenos Aires ${ }^{25}$ y una semana después, mientras estaba en Sao Paulo, le envió una carta a Jurgen Eick, editor del periódico alemán de corriente liberal Frankfurter Allgemeine Zeitung (FAZ). En ella le ofrece un breve artículo sobre Chile que se titularía "Internationaler Rufmord: Eine Personalische Stellungnahme" ("Calumnia internacional: una opinión personal"). ${ }^{26}$ El editor le responde rechazando su ofrecimiento. Eick argumenta que, si bien puede coincidir en lo sustantivo con el punto que Hayek quiere hacer, el artículo no lograría convencer a los escépticos y llevaría a sus

${ }^{25}$ En su visita a Buenos Aires, organizada por Alberto Benegas Lynch, Hayek se reunió con el Presidente general Videla el 22 de noviembre y también con el general Leopoldo Galtieri, entonces miembro de la junta militar. A fines de 1981, Galtieri reemplaza a Videla y en 1982 orquesta y lidera el conflicto de las islas Malvinas. Hayek apoya públicamente y con firmeza la reacción de Margaret Thatcher (carta al director The Times del 17 de febrero de 1983).

${ }^{26}$ Literalmente Ruf significa reputación o buen nombre, y Mord, asesinato. Entonces Rufmord tiene el sentido de matar el buen nombre o la reputación de alguien o algo. La correspondencia de Hayek con el FAZ se encuentra en la Hayek Collection, box 98, folder 13 . 
críticos a clasificarlo como un "Chile-Strauss". Esto último refiere a las duras críticas que recibieron las declaraciones del político alemán Franz Josef Strauss después de su visita a Chile.

Strauss declaró, después de una visita de cinco días a Chile, que estaba impresionado "por la paz doméstica y la estabilidad política" que había encontrado en Chile. Agregó que el gobierno de Pinochet, "si bien autoritario, no es dictatorial y es mucho menos brutal que otros regímenes militares en el mundo", aclarando, eso sí, que le había dicho "a Pinochet y otros miembros de la Junta que él estaba comprometido con la democracia parlamentaria y pensaba que los líderes en Chile deberían volver gradualmente a ese sistema" (Hoffman 1977, 4). Un grupo de sacerdotes alemanes reaccionaron ante estas declaraciones y un grupo de profesores universitarios hicieron un llamado al gobierno alemán para tomar acciones legales contra Strauss por "ayudar e incitar a una organización terrorista”, es decir, a la Junta Militar en Chile (Hoffman 1977, 4). Aunque Hayek había conocido a Strauss en una recepción en Chile, muy posiblemente no estaba al tanto de la controversia que se había generado en torno a la visita y a las palabras de Franz Josef Strauss.

Hayek le responde al editor del FAZ manifestándole su desilusión, y le ofrece su artículo como una carta al editor, de manera de eximir al periódico ante cualquier responsabilidad. Simplemente sería la opinión o el punto de vista de un lector, argumenta Hayek. Finalmente agrega que si bajo estas nuevas condiciones se negaba a publicarlo, lo enviaría a un journal conservador llamado Politische Studien. Su nueva propuesta también fue rechazada y el artículo fue finalmente publicado en 1978, bajo el título más breve de "Internationaler Rufmord", en el Politische Studien.

Es precisamente en este ensayo donde Hayek narra cómo gente bien intencionada le habría recomendado no viajar a Chile. Y agrega que en Chile conoció "gente muy educada, razonable e inteligente — personas que honestamente esperan que su país pueda regresar a un orden democrático pronto" (Hayek citado en Farrant et al. 2012, 518). Como Farrant y otros concluyen, el objetivo de Hayek en este ensayo no era defender a Pinochet o escribir un reporte de la situación económica y política en Chile, "sino argumentar que el régimen de Pinochet es injustamente sometido a una campaña de propaganda negativa" (517). En opinión de Hayek, la prensa internacional sistemáticamente distorsionaba la reali- 
dad tanto en Chile como en Sudáfrica. ${ }^{27}$ Más aún, afirma que los boicots y embargos contra estos países han sido arbitrarios, contradiciendo los principios que inspiran sus fundamentos (518).

Después de recibir el Premio Nobel, Hayek contribuyó con frecuencia al The Times de Londres a través de cartas al director. Sus cartas en las que critica los privilegios y las inmunidades legales de los sindicatos en Gran Bretaña generaron duras réplicas. También escribió acerca de la inmigración, inflación, monetarismo y diversos eventos políticos. El 11 de julio de 1978, en una de estas cartas al director, Hayek defendió a Margaret Thatcher, notando que cuando ella se refería a que "la libre elección debe extenderse más al mercado que a la urna, ella solamente manifestó una verdad, que la primera es indispensable para la libertad individual y la segunda no: la libre elección al menos puede existir bajo una dictadura que pueda autolimitarse, pero no bajo el gobierno de una democracia ilimitada". Esto provocó una reacción, en una carta publicada el 24 de julio, que lo acusaba de favorecer regímenes autoritarios.

Hayek respondió con otra carta, publicada el 3 de agosto. En ella escribe: "Ciertamente nunca he sostenido que generalmente los gobiernos autoritarios aseguran mejor la libertad individual que los democráticos, sino todo lo contrario. Esto no quiere decir, sin embargo, que en algunas circunstancias históricas la libertad personal no pudo haber estado más protegida bajo un gobierno autoritario que bajo una democracia". Para ilustrar este punto, Hayek acude a un mal ejemplo, argumentando que "en la Grecia antigua hubo más libertad individual bajo los 30 tiranos que en la democracia que mató a Sócrates, ${ }^{28}$ y más bajo Salazar en los comienzos de su gobierno en Portugal que en muchas democracias de Europa del Este, África y gran parte de Sudamérica”. Luego agregó la siguiente frase: "No he sido capaz de encontrar una sola persona en el desprestigiado Chile que no esté de acuerdo con que la libertad personal es mucho mayor bajo Pinochet que con Allende".

${ }^{27}$ Hayek y su mujer estuvieron en Sudáfrica algunos meses después de su viaje a Chile, entre el 13 de marzo y el 10 de abril de 1978.

${ }^{28}$ Karl Popper no hubiera estado de acuerdo con esta aseveración acerca de los 30 tiranos. En su Open Society and Its Enemies escribió: "El número de los ciudadanos asesinados por los treinta tiranos durante los primeros ocho meses de terror llegaron a ser aproximadamente 1.500, lo que, por lo que sabemos, no es menos que el 8 por ciento de la población total de ciudadanos que quedaron después de la guerra, o un 1 por ciento cada mes; un logro que ni siquiera ha sido sobrepasado en nuestros días" (Popper 1966, 303 n48). 
Un nuevo crítico, con crudo humor inglés, escribió que quizá era difícil encontrar adversarios si los habían matado. Lord Kaldor, su acérrimo enemigo, escribiría unos meses más tarde: "Si acogemos literalmente al profesor Hayek, una dictadura fascista de cualquier tipo debería ser considerada como una precondición necesaria (junto al monetarismo) de una 'sociedad libre" (The Times, 8 de octubre de 1978). Estos intercambios, incluyendo la carta de Kaldor, reflejan el tipo de reacciones que las palabras de Hayek generaban.

\section{ALGUNAS INTERPRETACIONES SOBRE HAYEK Y CHILE}

Antes de entrar en los detalles de la visita de 1981, es necesario detenerse en lo que se ha escrito respecto de las visitas de Hayek a Chile. Si la intención de este trabajo de investigación es entregar un relato de lo que realmente sucedió, es importante también detectar y corregir algunos errores y rebatir ciertas interpretaciones equivocadas..$^{29}$ No existe evidencia alguna para afirmar, como lo hacen Klein $(2007,103)$, Grandin $(2006,172)$ y Robin $(2011,74)$, que Hayek estuvo involucrado en la decisión para realizar la conferencia regional de la Mont Pèlerin Society en Viña del Mar el año 1981. Y contra el argumento de Fischer (2009), tampoco existe evidencia respecto de la eventual influencia de Hayek o sus ideas en la Constitución de 1980. Partamos por esto último.

\subsection{Hayek y la Constitución de 1980}

En efecto, Karin Fischer en su capítulo titulado "Authoritarian Freedom': A Hayekian Constitution for Chile” (“'Libertad autoritaria':

${ }^{29}$ Los errores e imprecisiones no merecen más que un pie de página. Por ejemplo, Hayek visitó Chile dos veces, no "muchas veces" (Klein 2007, 163) o "un número de veces" (Grandin 2006, 172). Hayek, que no pudo lograr una posición en el Departamento de Economía de la Universidad Chicago y cuyos puntos de vista difieren en una serie de temas sustantivos respecto a los de los miembros de dicha escuela, no puede ser descrito como "el santo patrón de la Escuela de Chicago" (Klein 2007, 103). El primer viaje de Hayek a Chile fue en 1977, no en 1978 (Fischer 2009, 328; Cristi 1998, 168; Cristi [2000] 2014, 185), y su publicación en alemán en el Politische Studien no se titulaba "True Reports on Chile" y no fue "una defensa de las políticas económicas y sociales bajo Pinochet" (Fischer 2009, 339), sino, como ya se ha explicado, una crítica sobre la cobertura negativa que recibía Chile en la prensa internacional. 
Una Constitución hayekiana para Chile") sostiene, como el título lo indica, que Hayek tuvo una influencia sustancial en el contenido de la Constitución de 1980, así como en el proceso de su creación:

La Constitución fue redactada por el gremialista Jaime Guzmán, quien desde del comienzo sirvió como el arquitecto del marco legal y constitucional del gobierno militar. La Constitución no sólo fue llamada como su libro La Constitución de la libertad, sino que también incorporó elementos significativos del pensamiento de Hayek [...]. Guzmán claramente tomó de Hayek la distinción entre autoritarismo y totalitarismo para justificar, cuando sean requeridas, el uso por parte del Estado de medidas represivas [...]. No debe sorprender que Hayek haya tenido que hacer un gran esfuerzo para otorgarle legitimidad a la nueva Constitución chilena, ya que en el proceso de redacción del borrador final fue consultado personalmente por el gobierno chileno. Durante su primera visita a Chile en 1978 [sic., la visita fue en 1977], Pinochet lo invitó a una entrevista personal. Un miembro de la comisión encargada de redactar la Constitución, Carlos Cáceres, era un cercano seguidor de Hayek y eventualmente se unió a la MPS en 1980. (Fischer 2009, 327-8) ${ }^{30}$

En este pasaje existen tres aseveraciones que requieren mayor reflexión. La primera es que Hayek fue consultado personalmente por el gobierno por el tema constitucional y que por eso se habría reunido con Pinochet. La segunda es que Jaime Guzmán, cuyo rol en la Constitución de 1980 está fuera de discusión, fue influenciado por las ideas de

${ }^{30} \mathrm{El}$ original en inglés dice: "The constitution was drafted by gremialista leader Jaime Guzmán, who from the beginning served as the architect of the legal and constitutional framework of the military government. The constitution was not only named after Hayek's book The Constitution of Liberty, but also incorporated significant elements of Hayek's thinking [...]. Guzmán clearly drew from Hayek in distinguishing between authoritarianism and totalitarianism in order to justify a state's use of repressive measures when they are required [...] Not surprisingly, Hayek went to some lengths to bestow legitimacy on the new Chilean constitution, since he had been personally consulted by the Chilean government in the process leading up to the final draft. During his first visit to Chile in 1978, Pinochet invited him to a personal meeting. Hayek's influence extended beyond the merely personal, however. One member of the commission in charge of drafting the constitution, Carlos Cáceres, was a close follower of Hayek and eventually joined the MPS in 1980". (Fischer 2009, 327-28) 
Hayek. Y la tercera pareciera ser que Hayek ejerció mayor influencia a través de su relación con Carlos Cáceres.

Respecto del primer argumento, la visita de Hayek en 1977 fue intensa, pero corta. No existió asesoría constitucional alguna. Y su encuentro con Pinochet, que personalmente no tuvo mayor impacto en la redacción de la Constitución, fue algo formal y breve. Los siguientes dos puntos, en cambio, requieren mayor elaboración y análisis.

Quizá conviene partir aclarando que en los setenta Hayek era prácticamente desconocido en Chile. ${ }^{31}$ Quienes sabían algo de su pensamiento habían leído su The Road to Serfdom (Camino a la servidumbre, 1944), pero no más allá. La mejor evidencia es que la historiadora Lucía Santa Cruz, en su entrevista a Hayek (El Mercurio, domingo 19 de abril de 1981) durante su segunda visita, parte con un error que refleja este punto. Hayek le muestra algunos capítulos de lo que sería su The Fatal Conceit: The Errors of Socialism, publicado posteriormente en 1988. Pero ella se refiere a "los últimos capítulos del tercer volumen de Ley, legislación y libertad", el que ya había sido publicado en 1979. De hecho, el rol de difundir el pensamiento de Hayek en Chile lo inició el CEP, y sólo comenzó cuando fue nombrado su presidente honorario en $1981 .{ }^{32}$ Por razones obvias, los libros de Milton Friedman Capitalism and Freedom (1962) y, posteriormente, su popular Free to Choose: A Personal Statement (1980) eran leídos y tuvieron gran influencia e impacto. En Chile, no ocurría en ese entonces lo mismo con The Cons-

${ }^{31}$ Una posible y notable excepción podría ser Jorge Millas. Su ensayo "La concepción de libertad-poder de Friedrich von Hayek" (Millas, 1996) iba a ser presentado en el seminario "El neoliberalismo y la experiencia chilena" en marzo de 1983, pero Millas murió en noviembre de 1982. En su dura crítica a la filosofía política de Hayek se basa en la tercera edición de los Fundamentos de la libertad, de Hayek, publicada en 1978, lo que sugeriría que su interés en Hayek tendría fecha posterior. Agustín Squella recuerda, en correspondencia privada: “[En 1981] Jorge Millas dio en Viña del Mar uno de sus cursos particulares, destinados a sobrevivir luego de ser exonerado de la universidad. Asistí, y el curso consistió en una crítica a Hayek". No hay que olvidar la activa participación de Millas contra la Constitución de 1980 y el plebiscito (ver su famoso "Discurso en el Teatro Caupolicán", publicado en El Mercurio el 30 de agosto de 1980).

32 En efecto, el primer volumen de la revista Estudios Públicos, de 1981, tiene una traducción de los capítulos 12, 16 y 18 de Law, Legislation and Liberty, Vol. 3, publicados bajo el título: "El ideal democrático y la contención del poder". Y ese mismo año se publica una colección de ensayos acerca de Hayek bajo el título $\mathrm{Ca}$ mino de libertad. 
titution of Liberty o los tres volúmenes de Law, Legislation and Liberty (1973, 1976 y 1979). ${ }^{33}$

Ciertamente Jaime Guzmán jugó un rol crucial en la Constitución de $1980 .{ }^{34}$ Pero diversos testimonios apuntan a que si bien tenía intereses intelectuales, el ex senador era finalmente un político. Por ejemplo, Arturo Fontaine, en su introducción a una selección de escritos de Jaime Guzmán publicados por la revista de Estudios Públicos un año después de su asesinato, parte su introducción declarando: "Jaime Guzmán no era un intelectual: era un político" (Fontaine 1991, 251). ${ }^{35}$ Aunque en la biblioteca de Guzmán había libros de Hayek, importantes testimonios cuestionan su influencia. ${ }^{36}$

Las dos mayores influencias en Guzmán eran el tomismo —una corriente intelectual profundamente arraigada en la Pontifica Universidad Católica de Chile y en el gremialismo- y muy posiblemente, como sostiene Cristi (1998; [2000] 2014, especialmente capítulo 3), las ideas del jurista alemán Carl Schmitt. En su Der Hüter der Verfassung (1931), que puede ser traducido como "El protector (o guardián) de la democracia", Schmitt desarrolla su idea de una democracia protegida, un concepto clave para Guzmán en su enfoque legal y cons-

33 Jorge Cauas, en una entrevista del 31 de marzo del 2014 con Leonidas Montes, reconoció la influencia de Friedman y admitió, en tanto, que él sólo había leído The Road to Serfdom y que no conocía muchas personas que hubieran leído más allá de este libro, con la excepción, quizá, de Hernán Cortés Douglas y Juan Carlos Méndez.

${ }^{34}$ En el reciente libro acerca de Carlos Cáceres se habla de Guzmán como el "autor intelectual principal de la Carta" (Arancibia 2014, 83).

${ }^{35}$ Moncada dice: "Guzmán fue ante todo un político. [...] su pensamiento estuvo constantemente adecuándose a la realidad que le tocó vivir" (Moncada 2006, 23). Renato Cristi, en el prefacio a la segunda edición de su biografía intelectual de Jaime Guzmán, matiza la imagen de su primera edición, aclarando que era un "pensador práctico" (Cristi [2000] 2014, 18).

${ }^{36}$ Agradecemos a Renato Cristi la información sobre las obras de Hayek en la biblioteca de Jaime Guzmán. No obstante, Enrique Barros, quien regresó a Chile en 1979 después de su doctorado en München, en correspondencia privada recuerda que entonces "Hayek era poco conocido en Chile" y que "muy probablemente Guzmán no lo había leído”. Óscar Godoy, quien había leído a Hayek a fines de los sesenta, en correspondencia privada afirma, de manera más categórica, "no haber encontrado, con la excepción de Pedro Ibáñez, ningún interlocutor para cruzar ideas sobre el autor [Hayek]" en los setenta en Chile. Y concluye: "Tengo la creencia que Hayek no tuvo ninguna presencia o impacto en Chile". 
titucional. ${ }^{37}$ Renato Cristi, en su fascinante y provocativa biografía intelectual de Jaime Guzmán, no sólo identifica la influencia de Tomás de Aquino y Carl Schmitt, sino que también agrega la importancia del carlismo español, que habría motivado la temprana admiración de Guzmán por Franco. ${ }^{38}$

En relación con el rol de Jaime Guzmán como el redactor de la Constitución de 1980 que le asigna Fischer (2009, 327), este juicio ignora que el proceso de elaboración de este texto fue bastante más complejo. Desde los inicios del régimen militar, Guzmán fue el asesor más influyente en asuntos legales y constitucionales. La "Declaración de principios del Gobierno de Chile" (11 de marzo de 1974) y el discurso de Chacarillas (9 de julio de 1977) fueron muy posiblemente íntegramente escritos por Guzmán. Su influencia en la Constitución de 1980 fue fundamental. Pero no estuvo solo en este proceso. En realidad, la Constitución fue el producto de un largo, lento y elaborado proceso que involucró a diversos actores.

Sólo dos días después del Golpe, la Junta Militar asignó a Jaime Guzmán la tarea de liderar un grupo de estudio de la Constitución (Cristi [2000] 2014, 45). ${ }^{39}$ Y diez días después del Golpe, la Junta Militar designó una comisión de abogados constitucionalistas para preparar un borrador de una nueva constitución. El grupo inicialmente se llamó "Comisión Constituyente", en seguida "Comisión de Estudio de la Nueva Constitución Política de la República" y finalmente sería conocida simplemente como "Comisión Ortúzar". Trabajó entre 1973 y 1978, cuando finalmente entrega su anteproyecto constitucional al Consejo de Estado. En septiembre de 1976, después del asesinato de Orlando Letelier, se agudizó la presión, tanto externa como interna, sobre la Comisión

${ }^{37}$ Pese a que Hayek sólo cita a Schmitt críticamente, Cristi (1998, capítulo 7) encuentra algunas similitudes entre ambos pensadores. Shearmur, en un paper pronto a publicarse, cuestiona esta interpretación. Lo cierto es que si Hayek promovía una "democracia limitada", ésta es muy distinta a la corporativista y paternalista "democracia protegida" de Carl Schmitt.

38 Sobre el carlismo, el movimiento católico, popular, conservador y tradicionalista que nace oficialmente en 1833, ver Blinkhorn (1975). También hay que destacar la influencia de José Antonio Primo de Rivera, el fundador, líder político y mártir de la falange española (Cristi [2000] 2014, 273-4).

${ }^{39}$ El Acta de la sesión del 13 de septiembre de la Junta de Gobierno dice: "Se encuentra en estudio la promulgación de una nueva Constitución Política del Estado, trabajo que está dirigido por el Profesor Universitario Dn. Jaime Guzmán”. 
Ortúzar. En julio de 1977, Pinochet se refirió, en su discurso de Chacarillas, a una transición y a una nueva constitución bajo la democracia protegida avalada por Guzmán. En noviembre de 1977, Pinochet envía las "Orientaciones básicas para el estudio de una nueva Constitución", lo que aceleró la discusión para tener una propuesta. Ahora bien, si todo esto era una simple estrategia o un gesto político, no lo sabemos. Pero finalmente se convirtió en un compromiso.

En enero de 1976 Pinochet había establecido el Consejo de Estado. Entre 1978 y 1980 este organismo revisó y corrigió el borrador de constitución que le hizo llegar la Comisión Ortúzar. Si bien con cierta frecuencia se ha argumentado que el régimen de Pinochet era personalizado, quizá tanto como el de Franco (ver Arriagada 1986; Huneeus 2007), la investigación seria y rigurosa de Robert Barros (1996; 2002; 2005) muestra que la Junta Militar impulsó leyes, reglas y procedimientos de manera colegiada. ${ }^{40}$ De hecho, Chile tradicionalmente ha sido un país legalista y el régimen militar no fue una excepción. Y las negociaciones que llevaron a la redacción de la Constitución de 1980 son sólo otro ejemplo de este fenómeno. Barros $(2005,208)$ afirma que la Constitución "fue el resultado de una negociación". ${ }^{41}$

Durante el debate constitucional, el fantasma de Allende, el marxismo y la crisis del gobierno de la Unidad Popular estaban muy presentes. Bajo el lema del orden y la paz, muchos mecanismos sumamente cuestionables, como el famoso artículo 8 derogado en 1989, fueron incluidos con el argumento de evitar otra crisis social y política. La "democracia protegida" implicaba un miedo a la mayoría que era compartido por casi todos los miembros de ambas comisiones. Y este miedo finalmente encontró su voz en la Constitución de 1980.

Todo esto nos trae de regreso a Pedro Ibáñez y Carlos Cáceres, los anfitriones de la visita de Hayek en 1977. El 7 de julio de 1978, Pedro Ibáñez le escribió a Hayek acerca del impacto de su primera visita.

${ }^{40}$ Ciertamente Pinochet quería obtener y asegurar el poder. Y si bien lo logró, existían límites. Por ejemplo, desde un comienzo había una clara delimitación de los poderes ejecutivo y legislativo (Barros 2002, 49-51; 2005, 72-4). Más aún, como Barros $(2002,38 ; 2005,63)$ argumenta, en materias legales se requería la unanimidad de los cuatro miembros de la Junta.

${ }^{41}$ La versión en inglés de Barros $(2002,167-8)$ afirma que, "contrario a la creencia popular de que la Constitución de 1980 fue diseñada y dictada por el general Pinochet", se trató más bien de "el producto de un compromiso". 
Destacó en su carta la importancia de su visita "ahora que existe un creciente debate sobre las nuevas instituciones políticas. Por lo tanto, sus ideas constantemente emergen como temas de frecuente discusión. Sin embargo el resultado final de los argumentos constitucionales están todavía lejos de ser claros”. Tanto Pedro Ibáñez como Carlos Cáceres eran miembros del Consejo de Estado. ${ }^{42}$ En marzo de 1979, Pedro Ibáñez presentó un memorándum al Consejo de Estado con una serie de comentarios para la nueva constitución. En una entrevista, Carlos Cáceres aseguró que dicho memorándum estaba inspirado por The Constitution of Liberty y por Law, Legislation and Liberty, de Hayek. ${ }^{43}$ Aunque Ibáñez y Cáceres promovieron algunas ideas hayekianas, en particular la de dos cámaras con dos propósitos diferentes, en lo fundamental se desvían del pensamiento hayekiano. En resumen, el memorándum finalmente proponía el sufragio limitado para un gobierno autocrático. ${ }^{44} \mathrm{El}$ presidente del Consejo de Estado, Jorge Alessandri, estuvo en completo desacuerdo. Y González Videla se refirió con mucho respeto a esta propuesta, calificándola de "totalitaria y fascista" (Arancibia, Brahm e Irarrázaval 2008, vol. 1, 416). Finalmente, sólo Ibáñez y Cáceres apoyaron el memorándum: el 3 de abril de 1979 el Consejo votó 13 contra 2 por rechazar las consideraciones de la propuesta de Pedro Ibáñez (Arancibia, Brahm y Irarrázaval 2008, vol. 1, 428-29). En resumen, lo que se conoció como el "voto de minoría" se oponía al sufragio universal, o lo "circunscribe", optando por "un sistema de elección indirecta o restringida" para elegir al Presidente, instituciones jerárquicas y autocráticas. ${ }^{45}$

42 El Consejo de Estado se inició con dieciséis miembros y su primera sesión fue el martes 20 de julio de 1976. Los ex Presidentes Jorge Alessandri y Gabriel González Videla actuaban como presidente y vicepresidente, respectivamente. Eduardo Frei Montalva no aceptó la invitación a participar, convirtiéndose en un activo y férreo opositor a la Constitución de 1980 y al plebiscito.

${ }^{43}$ Entrevista de Leonidas Montes con Carlos Cáceres, 5 de junio de 2014. Sobre este punto, desde la perspectiva de Carlos Cáceres, ver Arancibia (2014, 30-5).

${ }^{44}$ Para una discusión del memorándum y las actas del Consejo de Estado, ver Arancibia, Brahm e Irarrázaval (2008, vol. 1, 405-27). También Brahm (2008, lxxii1xxviii); Barros (2005, 266-68), y Sierra y MacClure (2011, 6-29).

${ }^{45}$ El "voto de minoría" plantea que "en ningún caso la elección de Presidente debería ser por elección popular", y propone: "Afianzar el carácter militar del régimen y restringir considerablemente la utilización del sufragio universal”. El texto completo, junto a la opinión disidente de Hernán Figueroa, se encuentra en El Mercurio, 10 de julio de 1980. Los autores afirman que el costo y la corrupción que introducen los partidos políticos a la vida pública "ha dado fundamento a Hayek para 
El 8 de julio de 1980, Jorge Alessandri presenta las recomendaciones del Consejo de Estado a Pinochet. ${ }^{46}$ La Junta Militar, muy posiblemente asesorada por Jaime Guzmán, revisa la propuesta y un mes después publica la versión definitiva en El Mercurio. Inmediatamente, el presidente del Consejo de Estado envía, en protesta por los cambios, una carta de renuncia a Pinochet. Alessandri apoyaba un Congreso transicional y elecciones en un plazo menor (Carrasco 1987, 139-41). ${ }^{47}$ Se eligió la fecha simbólica del 11 de septiembre para el plebiscito constitucional. Así, después de un "dudoso plebiscito que se lleva a cabo en medio de un estado de emergencia" (Barros 2002, 217), la Constitución de 1980 se aprobó. Posiblemente la frase "Constitución para la libertad" fue utilizada para promover la nueva Constitución, ${ }^{48}$ pero no correspondía a una invocación del libro de Hayek que lleva el mismo nombre, como plantea Karin Fischer. En el contexto de ese entonces, la libertad se reducía a la negación del marxismo. Y es precisamente ésa la señal que se quería enviar, no una referencia a un libro que muy pocos chilenos conocían.

La nueva Constitución mantuvo a Pinochet, ahora como Presidente constitucional de la República, por ocho años. Si bien la Constitución de 1980 tenía muchas disposiciones antidemocráticas, incluyendo la prohibición de los partidos políticos, también descansaba en la de 1925 . Pero fortalecía los derechos de propiedad y la libertad económica, estableciendo el rol subsidiario del Estado. ${ }^{49}$ La Constitución de 1980 ha sido criticada por muchas de sus provisiones, entre ellas el poderoso rol

describir el sufragio universal como soborno legalizado". Si bien Hayek fue muy crítico del poder de los sindicatos, de los funcionarios públicos y de los políticos, en sus obras, ya sea en The Road to Serfdom (1944), The Constitution of Liberty (1960), Law, Legislation and Liberty (1973, 1976, 1979), así como en sus colecciones de ensayos, no aparece esta aseveración o algo similar.

${ }^{46}$ El texto completo se publica el 9 de julio de 1980 en El Mercurio.

${ }^{47}$ En su carta de renuncia, Jorge Alessandri exigió que no se hiciera pública hasta después del plebiscito. Para entender el importante rol que jugó Alessandri basta leer las actas del Consejo y a Arancibia (2008, xxi-lxiii). Para un estudio comparado del proyecto constitucional del Consejo de Estado y la Constitución definitiva de 1980, ver Carrasco (1987, 147-223).

48 De hecho, la idea de "reafirmar nuestra libertad" convirtiendo "este 11 de septiembre en una nueva victoria para Chile", para rechazar "el regreso de los comunistas y los demás enemigos de la democracia que nos llevaron al borde de la guerra civil", fueron parte de la campaña.

${ }^{49}$ En una evaluación de derechos constitucionales, Ginsburg $(2014,14)$ afirma que la Constitución de 1980 tiene 16 derechos más que su predecesora, la Constitución de 1925. 
que les entregaba a las fuerzas armadas, las excepciones y sus manifiestas restricciones a la libertad política y civil (Loveman 1993, 353). Su origen autoritario también ha sido motivo de críticas, pero la verdad es que no es única en este aspecto. Se ha llegado a la conclusión empírica de que "hasta el año 2008 un 44 por ciento (79) de las constituciones vigentes en el mundo se pueden categorizar como democráticas y el restante 56 por ciento (79) como autoritarias" (Elkins et al. 2014, 145-6).

Collier y Sater resumen el asunto constitucional concluyendo que "el tenor de la versión final es marcadamente autoritario. Dentro de muchas cosas, entregaba un período presidencial extremadamente largo de ocho años (Pinochet quería 16 años, pero fue disuadido), un Congreso con poderes más limitados (y con un tercio de los senadores designados y no elegidos), y con varios mecanismos institucionales para atrincherar la influencia militar en los gobiernos futuros. Más aún, las 'disposiciones transitorias' (muy numerosas) estarían vigentes por casi una década" $(1996,364) .{ }^{50}$ Por último debe agregarse que si la Constitución de 1980 "aparecía como una obra de arte autoritaria" (Barros 2002, 217), también impuso nuevas restricciones a la autoridad de Pinochet. Y finalmente permitió un plebiscito que significó el retorno a la democracia. ${ }^{51}$

Como reflexión final, es posible que la biografía intelectual de Jaime Guzmán (Cristi [2000] 2014) haya influenciado algunas interpretaciones recientes, ya que en ella se plantea "la poderosa influencia del pensamiento de Hayek en Guzmán” (59). A partir de este juicio, la influencia de Hayek en la Constitución de 1980 parecería evidente. Sin embargo, nuestra investigación concluye que en los setenta la influencia de Hayek en Chile prácticamente no existía. Muy pocos intelectuales habían leído más allá de The Road to Serfdom. Y Guzmán, muy po-

${ }^{50}$ Como parte de las negociaciones hacia la transición, nuevos cambios se realizaron en 1989, los que fueron aprobados en el referéndum del 30 de julio de 1989 (Barros 2002, 308-10; para algunos aspectos fascinantes de este proceso, ver Godoy 1999). Con el retorno a la democracia, muchas disposiciones antidemocráticas fueron eliminadas. En efecto, desde entonces la Constitución de 1980 ha sido periódicamente modificada, con cambios mayores en el año 2005.

${ }^{51}$ La Constitución de 1980 creó instituciones, como el Tribunal Constitucional, que obligarían a la Junta Militar a efectuar un plebiscito debidamente regulado, permitiendo "una transición ordenada" (Ginsburg 2014, 14-6). La derrota de Pinochet en el plebiscito de 1988 implicaría el retorno a la democracia. Un notable grafiti de la época decía: "Lo echamos con un lápiz" (Barros 2002, 307). 
siblemente, no era una excepción. En conclusión, la conjetura de que las ideas de Hayek habrían influido en Guzmán y en la Constitución de 1980 no es consistente con la evidencia histórica.

\subsection{Hayek y la conferencia Mont Pèlerin Society en Viña del Mar}

Algunos autores han afirmado que Hayek, como fundador de la Mont Pèlerin Society, y en ese entonces su presidente honorario, eligió Viña del Mar para la conferencia regional de la sociedad en 1981.52 Veamos la información disponible al respecto.

Pedro Ibáñez y Carlos Cáceres le escribieron a Hayek para manifestarle la idea de realizar una conferencia de la Mont Pèlerin Society en Chile. De hecho, Cáceres le plantea que en la próxima conferencia en Hong Kong, en 1978, Pedro Ibáñez le propondrá al comité ejecutivo de la Mont Pèlerin Society realizar su encuentro general de 1980 en Chile. ${ }^{53}$ Y si bien al final Cáceres le pide su apoyo a Hayek, la carta de Pedro Ibáñez contiene más detalles y entrega algunos argumentos para realizarla en Chile. Dice Ibáñez:

El desarrollo económico y político de mi país puede ser valioso de revisar y analizar en el lugar.

Sin lugar a dudas, un grupo de destacados economistas, líderes de negocios y oficiales del gobierno, estarían muy contentos de cooperar y recibir a los miembros de la Sociedad.

52 Por ejemplo, Corey Robin afirma: "Hayek admiraba tanto a Pinochet que decidió realizar la conferencia de la Mont Pèlerin Society en Viña del Mar, el resort a orillas del mar donde el Golpe de Estado contra Allende se planificó" (Robin 2011, 74). Naomi Klein escribe que Hayek "viajó al Chile de Pinochet muchas veces y en 1981 eligió Viña del Mar (la ciudad donde se realizó la conspiración del golpe militar) para realizar la conferencia regional de la Mont Pèlerin Society, el cerebro de la contrarrevolución" (Klein 2007, 103). Greg Grandin también dice que Hayek "visitó el Chile de Pinochet un número de veces. Estaba tan impresionado que allí realizó una conferencia de su afamada Société du Mont Pèlerin”, e inmediatamente identifica a José Piñera, quien posee un $\mathrm{PhD}$ en economía en Harvard, como "un estudiante de Chicago" (Grandin 2006, 172). Ver también Robin (2012 ("The Road to Viña del Mar", http://coreyrobin.com/2012/07/17/the-road-to-vinadel-mar/)

${ }^{53}$ Carlos Cáceres a Hayek, 28 de abril de 1978, Hayek Collection, box 54, folder 23. Cabe aclarar que la conferencia general de la Mont Pèlerin Society no es lo mismo que una conferencia regional. 
Puedo asegurarle que el grupo chileno puede organizar un programa interesante y apropiado, incluyendo, de todas formas, entretenimiento para tan distinguido grupo.

Si bien Chile puede ser considerado por mucha gente como un país al fin del mundo, ¡dudo que Hong Kong esté más cerca!

Si usted comparte mi punto de vista, ¿cree que puedo contar con su respaldo y apoyo, cuando llegue el momento de plantear esta sugerencia al Consejo de la Sociedad? ${ }^{54}$

Pedro Ibáñez, con perseverancia y empuje, envió esta misma carta a los más altos representantes de la Mont Pèlerin Society, incluyendo a George Stigler, su presidente, y a Milton Friedman. No existe respuesta de Hayek a Pedro Ibáñez o a Carlos Cáceres en los archivos de Hayek ni en los Pedro Ibáñez Ojeda. En cambio, sabemos que Stigler contestó que el asunto "sería seriamente considerado por el consejo". Y Friedman respondió algo similar, agregando además que en su opinión personal sería mejor tener una conferencia regional en Chile, y no una general. ${ }^{55}$

No obstante, en la conferencia general de la Mont Pèlerin Society en Hong Kong en 1978, a la que Hayek asistió, se decidió que la próxima conferencia general sería en septiembre de 1980 en The Hoover Institution, en la Universidad de Stanford, Palo Alto. Y fue precisamente en esta conferencia general donde se decidió que la próxima conferencia regional sería en Viña del Mar, en septiembre o noviembre de 1981. Hayek no pudo asistir a dicha conferencia general por razones de salud y no existe evidencia de que haya participado en esta decisión. En cambio, Pedro Ibáñez y Carlos Cáceres sí asistieron a la conferencia en The Hoover Institution y plantearon su propuesta. ${ }^{56}$ Ésta fue acogida favorablemente mientras Manuel Ayau era presidente de la Mont Pèlerin Society. Después de más de dos años, la idea que Pedro Ibáñez ya había

${ }^{54}$ Carta Pedro Ibáñez a Hayek, 7 de julio de 1978, Hayek Collection, box 54, folder 23 .

55 Carta de George Stigler a Pedro Ibáñez, 4 de agosto de 1978; carta de Milton Friedman a Pedro Ibáñez, 22 de agosto de 1978; ambas en los archivos de Pedro Ibáñez Ojeda.

${ }^{56}$ Después de esta conferencia, Carlos Cáceres fue invitado a ser miembro de la Mont Pèlerin Society, ver Hayek Collection, box 72, folder 45 . 
comenzado a promover en julio de 1978 , se hizo realidad. ${ }^{57}$ La conferencia finalmente se realizó entre el 15 y 19 de noviembre de 1981, en Viña del Mar. Y contó con la asistencia de Rose y Milton Friedman, Arnold Harberger, James Buchanan y Gordon Tullock, entre otros. ${ }^{58}$

\section{HAYEK VISITA CHILE EN ABRIL DE 1981}

\subsection{La visita}

En 1981, para el segundo viaje de Hayek, tanto las circunstancias que lo rodearon como el contexto en Chile son diferentes. Era la época del milagro económico. El crecimiento económico entre 1975 y 1981 promediaba 7,3 por ciento. Y en 1981 la inflación alcanzaría sólo 9,4 por ciento. Además, la Constitución de 1980 traía la promesa de las elecciones en 1988.

El 26 de marzo de 1980, Jorge Cauas, entonces presidente del Banco de Santiago, le envía una carta a Hayek. Le escribe: "La economía ha continuado su mejoría descansando crecientemente en el libre mercado. Sin embargo estamos conscientes de la importancia de complementar este panorama económico con un análisis de aquellos aspectos que conforman, en sus palabras, la base de un orden político en una sociedad libre". Con esta inquietud, prosigue, él y un grupo de hombres de negocios están formando un centro dedicado al estudio de la "filosofía política, economía política y asuntos públicos", y que sobre la base de sus contribuciones en trabajos como The Constitution of Liberty y Law Legislation and Liberty les parece natural que busquen su apoyo y consejo, "como líder intelectual", para esta iniciativa. 59

${ }^{57}$ Cabe destacar que Pedro Ibáñez sugirió algunos invitados para la conferencia de la Mont Pelerin Society en The Hoover Institution, pero Milton Friedman junto a Manuel Ayau decidieron "no invitar a personas en posiciones de gobierno", por lo que, como medida "precautiva", tuvieron que "desinvitar" a Sergio de Castro, quien era ministro de Hacienda en ese entonces (carta de Manuel Ayau a Pedro Ibáñez, 28 de abril de 1980, archivo Pedro Ibáñez Ojeda).

${ }^{58}$ Las principales presentaciones de la conferencia regional de la Mont Pèlerin Society en Viña del Mar, junto a un ensayo de Hayek titulado "Los principios de un orden social liberal", fueron publicadas en la revista de Estudios Públicos 6, del segundo trimestre de 1982.

59 Carta de Jorge Cauas a Hayek del 26 de marzo de 1980, en Hayek Collection, box 15, folder 16 . 
Jorge Cauas visitó a Hayek en Friburgo a fines de mayo. Recuerda que se reunieron en el escritorio de su casa, donde hablaron por cerca de una hora. Cauas le pidió que fuera presidente honorario y miembro del consejo del Centro de Estudios Públicos (CEP). De acuerdo con Cauas, Hayek comprendió la importancia del proyecto para el futuro de Chile, aceptó la invitación para convertirse en su presidente honorario, y le dijo que consideraría seriamente una nueva visita a Chile. ${ }^{60}$

De regreso a Chile, en una carta del 5 de junio de 1980, Jorge Cauas le agradece que lo haya recibido y le informa sobre quiénes serán los demás miembros del consejo directivo del CEP. Además de los chilenos - Pablo Baraona, Jorge Cauas, Sergio de Castro, Arturo Fontaine A., Roberto Kelly, Julio Philippi y Carlos Urenda - han invitado a Karl Brunner, que aceptó; Armen Alchian, que lo está evaluando; como también a Milton Friedman, Ernst-Joaquim Mestmäcker, Arthur Seldon y Theodore W. Schultz. Cauas quería realizar la primera reunión del consejo que incluyera a los miembros extranjeros al año siguiente, dependiendo de la disponibilidad de Hayek. ${ }^{61}$ También le adjuntó los estatutos del CEP. Las bases generales establecían:

El propósito del Centro es el diagnóstico y análisis de los problemas filosóficos, políticos, sociales, económicos y públicos con el objeto de promover el entendimiento de los fundamentos que aseguran alcanzar y promover una sociedad libre.

Como Centro de pensamiento sustentado en las bases morales del mundo occidental, los valores que motivan sus acciones son aquellos que permiten la existencia de la más amplia libertad personal en una sociedad que vive en paz y armonía. Entonces el conjunto de valores que ordenan y centran el actuar del Centro le entregan prioridad a los ideales de la libertad.

El Centro implementará sus objetivos a través de estudios de investigación, publicaciones, seminarios y conferencias en las áreas de su interés. ${ }^{62}$

${ }^{60}$ Entrevista de Leonidas Montes a Jorge Cauas, 31 de marzo y 28 de mayo de 2014.

${ }^{61}$ Jorge Cauas era presidente del CEP; Julio Philippi, vicepresidente; Roberto Kelly, tesorero; Carlos Urenda, secretario; Hernán Cortés Douglas, director, y Juan Carlos Méndez, subdirector.

${ }^{62}$ Carta de Jorge Cauas a Hayek del 5 de junio de 1980, en Hayek Collection, box 15 , folder 16 . 
Hernán Cortés le escribió algunas cartas a Hayek, ya que no se sabía si finalmente viajaría a Chile. El 10 de octubre de 1980 Carlos Cáceres le envió una larga carta a Hayek, aparentemente respondiendo a algunas inquietudes que le habría manifestado antes de comprometerse a viajar a Chile. ${ }^{63}$ En su carta, Cáceres apoya decididamente a Jorge Cauas y la iniciativa del futuro CEP. Le cuenta que Cauas fue presidente del Banco Central bajo el gobierno de Frei Montalva, ${ }^{64}$ ministro de Hacienda de Pinochet entre 1975 y 1977, y después embajador ante los Estados Unidos entre 1977 y 1978. Cáceres alaba a Cauas por establecer el "sistema de economía libre" en un contexto difícil, agregando que "se necesitaba mucho coraje e ideas claras para tomar esas decisiones". Cáceres continúa diciendo que, desde su regreso de los Estados Unidos, Cauas se ha dedicado a congregar "un grupo de intelectuales para apoyar las ideas básicas de un sistema social libre". Para ello reunió a los miembros en el consejo del CEP, a quienes Cáceres identifica uno a uno. Su carta concluye con un fuerte apoyo a Cauas y al CEP, pidiéndole a Hayek aceptar la invitación de Cauas, que "le traerá prestigio al Centro". Y dice: "Creará un compromiso entre sus miembros en la constante búsqueda de las ideas que usted siempre ha avalado". 65

Cáceres también le menciona que la próxima conferencia regional de la Mont Pèlerin Society será en Viña del Mar en septiembre o noviembre de 1981. ${ }^{66}$ Dice: "Todos estaríamos muy contentos si usted pudiera participar de esta reunión. Por eso me gustaría proponerle que postergara su viaje a Chile para la fecha del encuentro, la que le confirmaré a la brevedad". No obstante, al apoyar a Jorge Cauas y al CEP, Carlos Cáceres estaba consciente de que sería muy improbable que Hayek viajara nuevamente a Chile a la conferencia regional de la Mont Pèlerin Society. De hecho, en una carta de Hayek a Cáceres, del 17

${ }^{63}$ Desgraciadamente, la supuesta carta de Hayek a Cáceres no se encuentra en los archivos de Hayek.

${ }^{64}$ Jorge Cauas fue vicepresidente del Banco Central entre 1967 y 1970, y su presidente fue Carlos Massad (este error se acarrea en Caldwell y Montes (2014)).

${ }^{65}$ Carta de Cáceres a Hayek del 10 de octubre de 1980, en Hayek Collection, box 54 , folder 23 .

${ }^{66}$ El que Cáceres le mencione a Hayek que la conferencia regional de la Mont Pèlerin Society será en Viña del Mar “en septiembre o noviembre de 1981" avala la tesis de que Hayek no habría estado involucrado en la decisión. 
febrero de 1980, ya se lo había dejado claro: "Después de visitar Sudamérica esta primavera existen muy pocas posibilidades de que pueda repetir este viaje en el otoño para asistir a la Mont Pèlerin en Viña del Mar“ ${ }^{67}$ El 8 de mayo de 1981 Hayek cumpliría 82 años.

Finalmente Hayek decidió realizar otro viaje a Sudamérica. El 20 de octubre de 1980 les envía una carta a todos los involucrados en su próximo viaje (Cauas, Cortés y Cáceres en Chile, Maksoud en Brasil y Benegas Lynch en Argentina), en la que les informa que visitaría Sudamérica con su mujer "desde mediados de abril hasta mediados de mayo". Dice que visitará Chile primero, y concluye: "Me temo que tengo que implorarles que la cantidad de trabajo que ahora puedo realizar es algo limitada, aunque por supuesto estaré disponible para hablar en dos o tres ocasiones durante mi estadía en cada uno de los tres países". 68

Acompañado de su mujer, Hayek regresa a Chile el miércoles 15 de abril de 1981. Su carga de compromisos, en comparación con la visita anterior, fue mucho menor. Además, era semana santa, por lo que las actividades sólo comenzaron el lunes 20 de abril con el consejo ampliado del CEP. Para el martes tenía una visita a la Pontificia Universidad Católica de Chile y ese mismo día, por su propia iniciativa, Hayek tuvo una reunión privada con Eduardo Frei Montalva. ${ }^{69}$ En los dos días siguientes participó de la conferencia organizada por el CEP titulada "Fundamentos de un sistema social libre", en el hotel Sheraton de Santiago. El evento recibió amplia cobertura. Los miembros extranjeros del consejo del CEP, incluyendo a Hayek, presentaron sus trabajos. Después de una bienvenida de Jorge Cauas, Nishiyama comenzó la conferencia el miércoles en la mañana, con el ensayo "Expectativas racionales y sistema social libre", seguido de Schultz con "El problema de la pobreza en la sociedad libre". El jueves fue el turno de Mestmäcker con "Libertad y monopolio en la economía y los medios de comunicación"; Alchian habló de "La importancia de los derechos de propiedad en una

${ }^{67}$ Carta de Hayek a Cáceres del 17 de febrero de 1980, en Hayek Collection box 54 , folder 23 .

${ }^{68}$ Carta de Hayek a Cáceres del 20 de octubre de 1980, en Hayek Collection box 15 , folder 16 .

${ }^{69}$ La Segunda del 21 de abril de 1981 relata que la visita fue solicitada por Hayek y que llegó a casa de Frei Montalva sólo con una traductora. 
sociedad libre", y Hayek cerró el evento con "Los fundamentos éticos de una sociedad libre". ${ }^{70}$

El viernes 24 de abril, Hayek se reunió con Jorge Alessandri. Después del encuentro declaró: "Alessandri y yo pensamos parecido" ( $L a$ Segunda, 24 de abril de 1981, y El Mercurio, 25 de abril de 1981). Ese mismo viernes, Hayek tuvo una entrevista con Jaime Guzmán, Ernesto Illanes y Hernán Larraín, la que fue publicada en la revista Realidad (n. ${ }^{\circ}$ 24, mayo 1981, 27-35). Algunas de las ideas de Hayek acerca de la ley natural y la Iglesia Católica evidentemente contrastaban con el gremialismo, pero en esta entrevista básicamente repite lo que ha dicho en otras, donde cabe destacar sus dos largas entrevistas para El Mercurio. ${ }^{71}$ Sin embargo, en la página 28 los entrevistadores de Realidad colocan un recuadro con varios nombres y algún comentario corto de Hayek acerca de cada persona. Por ejemplo, sobre el "Presidente A. Pinochet" habría dicho: "un general honorable"; sobre Frei Montalva, con quien se había reunido hace sólo tres días: "conozco el tipo de persona"; y acerca de Karl Popper, Hayek supuestamente habría dicho: "mi mejor amigo", lo que resulta sorprendente, ya que Hayek nunca antes había identificado a Popper como su mejor amigo. De hecho, siempre incluyó en esta categoría sólo a Walter Magg, su amigo de la niñez, y a su colega del LSE, el economista Lionel Robbins.

En seguida, el mismo viernes Hayek viajó a Viña del Mar para participar en una reunión de planificación para la conferencia regional de la Mont Pèlerin Society y dictó una clase a un grupo de estudiantes de la Escuela de Negocios de Valparaíso. El sábado almorzó en Colunquén, el campo de Pedro Ibáñez, tal como lo había hecho en su visita anterior. El domingo paseó con su mujer por Viña del Mar, y en la tarde participó en la inauguración y cóctel de una conferencia organizada por Miguel Kast titulada: "Conferencia internacional sobre experiencias de política económica”. Ésta se realizó en el hotel Miramar, comenzó el lunes y en la primera sesión de la mañana Hayek habló acerca del "Rol

${ }^{70}$ Este ensayo de Hayek sería publicado en Estudios Públicos 3, de 1981.

${ }^{71}$ Estas son la de Renée Sallas, periodista argentina, en El Mercurio, domingo 12 de abril de 1981, y la de Lucía Santa Cruz en El Mercurio, domingo 19 de abril de 1981. Para un breve análisis, el lector interesado puede consultar Caldwell y Montes (2014), sección 8. 
de las instituciones internacionales". ${ }^{72}$ El martes 28 de abril dio su última clase en la Escuela de Negocios de Valparaíso, y en la tarde viajó a Buenos Aires, Argentina.

\subsection{Hayek y Chicago}

Es interesante que las actas de la reunión de consejo ampliado del lunes 20 de abril de 1981 revelan ciertas tensiones entre los miembros sobre el futuro del CEP. En la invitación inicial de Jorge Cauas la preocupación por la filosofía política, los asuntos públicos y los problemas constitucionales era evidente. Este sentido y objetivo estaba también explícito en los estatutos de la organización, donde se especifica que el CEP se centraría en "temas filosóficos, políticos, sociales, económicos y en asuntos públicos". Esta motivación obedecía a que estos problemas estaban presentes con el nuevo contexto político iniciado por la Constitución de 1980. No obstante este amplio mandato, las actas del consejo al que asistió Hayek como presidente honorario del CEP dejan constancia de la influencia de los Chicago Boys:

La discusión se centró en las sugerencias de los miembros del Consejo Schultz y Alchian para concentrar los esfuerzos del Centro en áreas económicas quitando énfasis al área de la filosofía y teoría política. Hubo acuerdo en dedicar los esfuerzos del Centro hacia problemas económicos y mantener la Revista Estudios Públicos para propósitos multidisciplinarios.

Cuando la atención se sitúa en posibles temas para futuros seminarios, la división emerge nuevamente:

El profesor Mestmäcker enfatizó temas acerca de la Constitución y los profesores Alchian y Schultz enfatizan problemas sociales

72 Después de almuerzo, en un panel moderado por Carlos Cáceres titulado "Chile en los últimos 10 años", Jorge Cauas hizo una presentación acerca de "Política fiscal y económica"; Sergio de la Cuadra tocó la "Política de comercio exterior"; Arnold Harberger, "La política económica y el tipo de cambio real", y Florencio Ballesteros, economista principal de la OEA, "Perspectivas futuras para Chile en los organismos internacionales". El martes presentaron Larry Sjaastad (Chicago), Sam Peltzman (Chicago) y Armen Achian (UCLA). El miércoles fue el turno de John Pencavel (Stanford), H. Gregg Lewis (Duke), Daniel Gressel (Chicago) y Martin Bailey (Maryland). Los comentarios de cierre fueron del ministro de Hacienda, Sergio de Castro (Hayek Collection, box 4, folder 33). 
con un foco en la economía, como pobreza, capital humano, distribución del ingreso, además de los problemas económicos relacionados a diversas instituciones; gobierno local y legislación acerca de empresas públicas. Los estudios sobre organización industrial realizados en UCLA serán especialmente importantes para esto último.

Estas diferencias, de hecho, ya habían sido anticipadas en un editorial de El Mercurio del 22 de noviembre de 1977, sólo dos días después de que Hayek viajara a Buenos Aires luego de su primera visita a Chile. El editorial concluye que "la política del Gobierno no pertenece de suyo a la escuela de Chicago ni a ninguna otra en particular". Las diferencias de Hayek con Friedman ya habían aparecido también en la entrevista de revista Ercilla. Al ser consultado por su opinión de Milton Friedman y del monetarismo, Hayek responde:

Milton Friedman es un viejo amigo mío. Coincido con él en lo general, pero hay dos puntos en los cuales discrepo. Friedman es un positivista estricto y le da demasiada importancia a los datos estadísticos. Esta interpretación macroeconómica es inútil. Sólo la microeconomía puede importar en economía. En cuanto a la teoría cuantitativa del dinero, es excelente, pero muy simple. Demasiado simple. (Ercilla, noviembre 23 de 1977)

En la notable entrevista de Lucía Santa Cruz en El Mercurio, durante la segunda visita de Hayek en 1981, estas diferencias se reiteran. Conviene reproducir parte de esta conversación:

LSC: Ahora, tradicionalmente el liberalismo ha sido una mentalidad más que una doctrina rígidamente estructurada, un enfoque pragmático y empírico, una aplicación del principio "trial and error". Hay personas que creen que el neoliberalismo es esencialmente distinto en este respecto, porque ofrece una estructura muy sólida que podría clasificarse como una ideología muy coherente y global. ¿Cómo se puede compatibilizar eso, por ejemplo, con la idea de ese gran liberal Karl Popper de que la política, al igual que una hipótesis científica, es sólo una verdad conjetural, sin valor de verdad última?

FAH: Popper y yo estamos de acuerdo en casi todos los respectos. El problema es que no somos neoliberales. Quienes así se 
definen no son liberales, son socialistas. Somos liberales que tratamos de renovar, pero nos adherimos a la vieja tradición, que se puede mejorar, pero que no puede cambiarse en lo fundamental. Lo contrario es caer en el constructivismo racionalista, en la idea de que se puede construir una estructura social concebida intelectualmente por los hombres, e impuesta de acuerdo a un plan, sin tener en consideración los procesos culturales evolutivos.

LSC: ¿No cree usted que en el caso chileno, por ejemplo, donde se está tratando de aplicar un modelo muy coherente en todas las esferas de la vida nacional, se dan algunos rasgos de eso que usted llama constructivismo?

FAH: No conozco lo suficiente para opinar. Sé que los economistas son sólidos.

LSC: Pero el modelo abarca más que la mera economía...

FAH: Es posible que eso se deba a la enorme influencia que el positivismo y el utilitarismo han tenido en Latinoamérica. Bentham y Comte han sido las grandes figuras intelectuales del continente y el liberalismo en este continente siempre ha sido constructivista. Milton Friedman, por ejemplo, es un gran economista con el cual concuerdo en casi todos los puntos, pero discrepo no sólo en el uso mecánico del circulante. Yo también soy economista, pero me gusta pensar que soy algo más que eso. Yo siempre digo que un economista que es sólo un economista, ni siquiera puede ser un buen economista. Bueno, Friedman se crió en la tradición del Bureau of Economic Research bajo la influencia de Mitchel. Éste sostiene que, puesto que nosotros hemos creado las instituciones, podemos cambiarlas como queremos. Esto es una equivocación intelectual. Es un error. Es falso. En este sentido, Milton es más constructivista que yo. (El Mercurio, domingo 19 de abril de 1981)

A partir de la provocativa y sorprendente afirmación de Hayek — "no somos neoliberales"- y su fundamentación, surge otra interesante interpretación. El historiador Mario Góngora percibe, en su lectura de esta entrevista, las diferencias entre Hayek y los Chicago Boys. Finaliza su influyente y controvertido Ensayo histórico sobre la noción de Estado en Chile en los siglos XIX y XX, publicado ese mismo 1981, con la siguiente reflexión:

¿Es compatible el liberalismo como idea con la planificación de un sistema liberal en un país en el cual esa idea no está incor- 
porada en la tradición? Friedrich von Hayek, al responder a una pregunta sobre su afinidad con el pensador liberal Karl Popper, dice terminantemente que no: "El problema es que no somos neoliberales. Quienes así se definen no son liberales, son socialistas. Somos liberales que tratamos de renovar, pero nos adherimos a la vieja tradición, que se puede mejorar, pero que no puede cambiarse en lo fundamental. Lo contrario es caer en el constructivismo racionalista, en la idea de que se puede construir una estructura social concebida intelectualmente por los hombres, e impuesta de acuerdo a un plan, sin tener en consideración los procesos culturales evolutivos". A continuación señala, con buen conocimiento de la historia latino-americana, que este constructivismo puede deberse en parte al influjo del Utilitarismo de Bentham y al Positivismo. Y de Friedman dice que se formó en una escuela donde se enseñaba que, puesto que hemos creado instituciones, también las podemos cambiar cuando queramos.

[...] El espíritu del tiempo tiende en todo el mundo a proponer utopías (o sea, grandes planificaciones) y a modelar conforme a ellas el futuro. Se quiere partir de cero, sin hacerse cargo de la idiosincrasia de los pueblos ni de sus tradiciones nacionales o universales; la noción misma de tradición parece abolida por la utopía. En Chile la empresa parece más fácil cuanto más frágil es la tradición. Se va produciendo una planetarización o mundialización, cuyo resorte último es técnico-económico-masivo, no un alma.

En seguida remata su ensayo con las siguientes palabras:

En la inacabable crisis del siglo XX, que puede ser mirada desde diversos ángulos, hemos querido señalar en este ensayo tan solamente una, la crisis de la idea de Estado en Chile: es decir, la de una noción capital de nuestro pueblo, ya que es el Estado el que le ha dado forma a nuestra nacionalidad. (Góngora 1981, 137-8)

Mario Góngora, férreo opositor al principio de subsidiariedad, critica al neoliberalismo constructivista o lo que él llama la "revolución desde arriba" ${ }^{73}$ Y para ello, finaliza su ensayo destacando el contraste entre el pensamiento de Hayek y el enfoque económico de los Chicago

${ }^{73}$ Aunque al igual que Jorge Millas, Góngora es crítico de lo que sucede en educación, sobre todo en las universidades, es notable la diferencia con que ambos intelectuales interpretan a Hayek (cf. nota 31) 
Boys. Ciertamente, la crítica hayekiana a los modelos y la planificación — todas ideas más propias de la Escuela de Chicago - es lo que tiene que haber llamado la atención del historiador. Son las diferencias entre el Old Whig, que admira la tradición de la ilustración escocesa y desconfía de los expertos, y el utilitarismo de Bentham, que cree conocer las recetas y las soluciones aplicando el principio de la mayor felicidad del mayor número. ${ }^{74}$ En definitiva, la última es una mirada más dogmática y reduccionista, que contrasta con una mirada más escéptica de la realidad, que desconfía del uso y abuso de la razón. ${ }^{75}$

Evidentemente, las diferencias metodológicas entre Friedman y Hayek son sustantivas. Por de pronto, está la oposición entre la economía positiva de Friedman, con su énfasis en el carácter predictivo, y la concepción hayekiana que reconoce la complejidad de los fenómenos sociales, políticos y económicos. Por otro lado, si Hayek es un crítico de la caricatura del homo economicus, la racionalidad económica es la base de la economía neoclásica que inspira a la Escuela de Chicago. En resumen, el contraste se encuentra entre el foco económico, más propio de Chicago, y la insistencia de Hayek en el marco más amplio de la institucionalidad política, legislativa y judicial. Estas divergencias son un tema muy interesante que recorre la historia de la Mont Pèlerin Society. ${ }^{76} \mathrm{Y}$ lo fascinante es que también emergen en Chile de manera espontánea.

La influencia de Hayek como presidente honorario del CEP se extendió más allá de la formalidad de su cargo. Su presencia contribuyó a la discusión en torno a la filosofía política, los temas públicos, filosóficos y culturales. Esta apertura, que no sólo reducía su ámbito de acción a la economía, fue particularmente importante desde la creación del CEP. Por ejemplo, Puryear, en su análisis del rol de los intelectuales y think tanks durante la transición chilena, se refiere al CEP en los siguientes términos:

[Fue] virtualmente el único think tank de centro-derecha que surge en los 1980s. El CEP fue fundado en 1980 por un grupo de

${ }^{74}$ El utilitarismo, no debemos olvidarlo, es la base filosófica de la economía neoclásica.

${ }^{75}$ Hayek, que provenía de una familia católica, fue un agnóstico. Al final de su entrevista con Renée Sallas del domingo 12 de abril de 1981 en El Mercurio, Hayek manifiesta con elegancia su posición.

${ }^{76}$ Burgin (2012) investiga las tensiones en la Mont Pèlerin Society entre los seguidores de Hayek, con una mirada más abierta a los problemas políticos y sociales, y los de Friedman, con un énfasis más económico. 
economistas y líderes de negocios que buscaban ampliar la legitimidad del pensamiento político neoconservador distanciándose del régimen militar. Completamente independiente del gobierno, el CEP dependía del apoyo de grupos económicos y donantes extranjeros. Era una empresa intelectual seria, convocando a top scholars y policymakers para discutir asuntos políticos, sociales y económicos [...]. El CEP ayudó a establecer la identidad y legitimidad de la derecha democrática, y generar un diálogo con intelectuales de centro e izquierda. (Puryear 1994, 91)

\subsection{Otras controversias}

Así como Hayek tuvo sus controversias con la prensa en su visita de 1977, su segunda visita no estaría exenta de polémica. El 30 de diciembre de 1981, el Frankfurter Allgemeine Zeitung (FAZ) publicó una caricatura de Fritz Bahrendt (1925-2008), un famoso caricaturista político de la época conocido por su rechazo a las dictaduras, mostrando a Pinochet y a Jaruzelski, el dictador polaco, ambos montando y espoleando a sus caballos exhaustos, que representaban a Chile y Polonia (Hallo, Kollege). ${ }^{77}$

Una carta crítica de Hayek fue publicada en el FAZ el 6 de enero de 1982:

No puedo sino protestar en los más duros términos contra la caricatura de la página 3 de su publicación del 30 de diciembre en la que se igualan los gobiernos de Polonia y Chile. Sólo puede explicarse por completa ignorancia de los hechos o por las calumnias promovidas por el socialismo acerca de la situación actual en Chile, la que no habría esperado del Frankfurter Allgemeine Zeitung. Creo que todos los participantes en la conferencia de la Mont Pèlerin Society, que se realizó en Chile unas semanas atrás, estarían de acuerdo conmigo en que le deben una humilde disculpa al gobierno de Chile por ese error de hecho. Cualquier polaco se sentiría afortunado de escapar a Chile. ${ }^{78}$

${ }^{77}$ Es importante recordar que recién el 13 de diciembre de 1981 Jaruzelski había decretado ley marcial en Polonia.

${ }^{78}$ Hayek envió copias de la caricatura y su carta a Pedro Ibáñez, Miguel Kast, Carlos Cáceres y Hernán Cortés. Existen respuestas de Carlos Cáceres (carta del 12 febrero de 1982, Hayek Collection, box 54, folder 23) y Pedro Ibáñez (carta del 19 febrero de 1982, Hayek Collection, box 63, folder 8). 


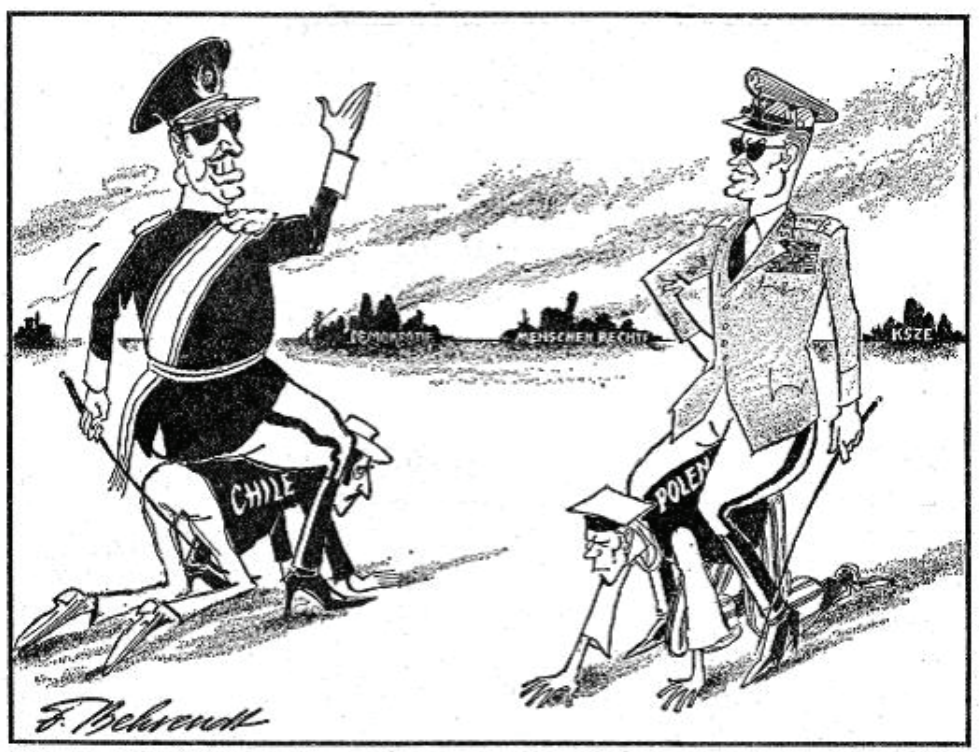

Hallo, Kollege

Por último, es importante mencionar la famosa carta de Margaret Thatcher a Hayek de esta misma época, en la que se refiere "al notable ejemplo de las reformas económicas [en Chile] de la cuales debemos aprender muchas lecciones". Pero en esta carta continúa diciendo que Hayek estaría de acuerdo con ella en que "en Gran Bretaña, con nuestras instituciones democráticas y la necesidad de un alto grado de consenso, algunas de las medidas adoptadas en Chile serían inaceptables". Thatcher reconoce que el proceso democrático se mueve lentamente, pero expresa su confianza: "Nosotros lograremos nuestra reformas a nuestra manera y en nuestro tiempo", y que éstas perdurarán. ${ }^{79}$

Tanto Charlotte Cubitt (2006) como Farrant et al. (2012, 535 N. 35) sostienen que la palabras de Thatcher serían en respuesta a una carta de Hayek para protestar por la caricatura del FAZ. De hecho, Thatcher le agradece su misiva del 5 de febrero. Pero no existe copia alguna de dicha carta ni en los archivos de Hayek, ni en los de Thatcher. No obstante, al comienzo de su carta, Thatcher dice que fue grato verlo la semana anterior en Londres en la comida organizada por Walter So-

79 Carta de Thatcher a Hayek del 17 de febrero de 1982, Hayek Collection, box 101, folder 26 . 
lomon y escuchar los puntos de vista de Hayek acerca "de los grandes problemas de nuestro tiempo". Esto sugiere que la carta de Thatcher también pudo ser en respuesta a algo que se dijo en alguna conversación durante esa comida. Aunque no tenemos evidencia de lo que sucedió en esa cena, o de si efectivamente existe una carta que se perdió, la hipótesis sugerida por Farrant et al. (2012) respecto de que "Hayek habría urgido a Thatcher a prohibir las huelgas o limitarlas severamente" (535 n35) es una posibilidad como cualquier otra, especialmente considerando que Hayek sostenida y repetidamente criticó el poder de los sindicatos en Gran Bretaña.

\section{CONCLUSIONES}

Durante su primera visita, en noviembre de 1977, invitado por la Universidad Técnica Federico Santa María y Pedro Ibáñez Ojeda, Hayek quedó impresionado por lo que se estaba haciendo en Chile en materias económicas, convenciéndose de que había un sesgo de la prensa internacional en contra de Chile. Esto lo motivó a escribir la carta al FAZ mientras todavía se encontraba viajando.

Respecto de su eventual influencia, Hayek era muy poco conocido en los setenta en Chile. Por lo tanto es improbable, como sugiere Cristi ([2000] 2014), que Hayek haya tenido influencia en Jaime Guzmán y en la Constitución de 1980. Pedro Ibáñez y Carlos Cáceres, quienes conocían a Hayek, no necesariamente interpretaron sus ideas. Y recién a partir de 1981 comienza a difundirse el pensamiento de Hayek en Chile, gracias a una serie de traducciones que se publicaron en la revista Estudios Públicos. Sólo entonces sus ideas adquirieron mayor peso e importancia.

Su segundo viaje, en abril de 1981, fue diferente. Hayek regresa a un Chile donde el éxito de la liberalización económica, aunque efímero, parecía evidente, y donde la situación política después de la Constitución de 1980 permitía prever una transición a la democracia. En esta ocasión fue invitado por Jorge Cauas para asumir como presidente honorario del CEP. Algunos miembros de este centro de estudios, entre ellos su presidente, Jorge Cauas, y su director ejecutivo, Hernán Cortés Douglas, estimaban que la filosofía política y social de Hayek podía ser importante para el futuro de Chile. 
Si bien el rol del CEP estaba ampliamente definido en sus estatutos como el "diagnóstico y análisis de los problemas filosóficos, políticos, sociales, económicos y públicos", no existía consenso al interior del consejo directivo respecto de la dirección que debía seguir esta institución. Los Chicago Boys pretendían mantener el énfasis en los temas económicos por sobre los temas políticos, públicos y sociales. Finalmente, a juzgar por el rol que jugó el CEP durante la transición, fue el legado de Hayek el que prevaleció.

\section{REFERENCIAS BIBLIOGRÁFICAS}

Arancibia, Jaime. 2008. "Lecciones de un estadista 'práctico'. El aporte de Jorge Alessandri al debate del Consejo de Estado sobre la Constitución de 1980". En Actas del Consejo de Estado en Chile (1976-1990) Vol. 1, de Jaime Arancibia, Enrique Brahm \& Andrés Irarrázaval. Santiago de Chile: Centro de Estudios Bicentenario.

Arancibia, Jaime, Enrique Brahm \& Andrés Irarrázaval. 2008. Actas del Consejo de Estado en Chile (1976-1990). Santiago de Chile: Centro de Estudios Bicentenario.

Arancibia Clavel, Patricia. 2006. Cita con la historia. Santiago de Chile: Editorial Biblioteca Americana.

Arancibia Clavel, Patricia. 2014. Carlos F. Cáceres. La transición a la democracia 1988-1990. Santiago de Chile: Ediciones LYD.

Arancibia, Patricia \& Francisco Balart. 2007. Sergio de Castro. El arquitecto del modelo económico chileno. Santiago de Chile: Editorial Biblioteca Americana.

Arriagada, Genaro. 1986. "The Legal and Institutional Framework of the Armed Forces in Chile." En Military Rule in Chile: Dictatorship and Oppositions, editado por J. Samuel Valenzuela \& Arturo Valenzuela. Baltimore, Maryland: Johns Hopkins University Press.

Barros, Robert. 1996. "By Reason and Force: Military Constitutionalism in Chile 1973-1989." PhD dissertation, Department of Political Science, University of Chicago.

- 2002. Constitutionalism and Dictatorship. Pinochet, the Junta, and the 1980 Constitution. Cambridge: Cambridge University Press.

—. 2005. La Junta Militar: Pinochet y la Constitución de 1980. Santiago de Chile: Editorial Sudamericana.

Blinkhorn, Martin. 1975. Carlism and Crisis in Spain: 1931-1939. Cambridge: Cambridge University Press.

Brahm, Enrique. 2008. "Régimen de gobierno y cuestionamiento del sufragio universal en las Actas del Consejo de Estado 1978-1980." En Actas del Consejo de Estado en Chile (1976-1990) Vol. 1, de Jaime Arancibia, 
Enrique Brahm \& Andrés Irarrázaval. Santiago de Chile: Centro de Estudios Bicentenario.

Burgin, Angus. 2012. The Great Persuasion: Reinventing Free Markets since the Depression. Cambridge: Harvard University Press.

Caldwell, Bruce. 2011. "The Chicago School, Hayek and Neoliberalism". En Building Chicago Economics: New Perspectives on the History of America's Most Powerful Economics Program, editado por Robert Van Horn, Philip Mirowski \& Thomas A. Stapleford. Cambridge: Cambridge University Press.

Caldwell, Bruce \& Montes, Leonidas. 2014. "Friedrich Hayek and his Visits to Chile." Review of Austrian Economics (on line). http://link.springer.com/articl e/10.1007\%2Fs11138-014-0290-8. Por publicarse en versión impresa.

Carrasco, Sergio. 1987. Alessandri. Su pensamiento constitucional. Reseña de su vida pública. Santiago de Chile: Editorial Jurídica de Chile.

Collier, Simon \& William F. Sater. 1996. A History of Chile, 1808-1994. New York y Cambridge: Cambridge University Press.

Cristi, Renato. 1998. Carl Schmitt and Authoritarian Liberalism. Cardiff: University of Wales Press.

—. [2000] 2014. El pensamiento político de Jaime Guzmán. Una biografía intelectual. Santiago de Chile: LOM Editores.

Cristi, Renato \& Pablo Ruiz-Tagle. 2006. La república en Chile. Teoría y práctica del constitucionalismo republicano. Santiago de Chile: LOM Editores.

Cubitt, C. E. 2006. A Life of Friedrich August von Hayek. Bedfordshire: Authros OnLine Ltd.

Díaz, José, Rolf Lüders \& Gert Wagner. 2014. La República en cifras. Chile, 18102010. EH Clio Lab, Pontificia Universidad Católica de Chile. http://www. economia.puc.cl/cliolab

Elkins, Zachary, Tom Ginsburg \& James Melton. 2014. "The Content of Authoritarian Constitutions." En Constitutions in Authoritarian Regimes, editado por Tom Ginsburg \& Alberto Simpser. Cambridge: Cambridge University Press.

Farrant, Andrew \& Edward McPhail. 2014. "Can a Dictator Turn a Constitution into a Can-opener? F. A. Hayek and the Alchemy of Transitional Dictatorship in Chile." Review of Political Economy 26 (3): 331-348.

- Manuscrito. "Hayek, Thatcher, and the Muddle of the Middle."

Farrant, Andrew, Edward McPhail \& Christian Berger. 2012. "Preventing the 'Abuses' of Democracy: Hayek, the 'Military Usurper', and Transitional Dictatorship in Chile." American Journal of Economics and Sociology 71: 513-38.

Fischer, Karin. 2009. "The Influence of Neoliberals in Chile Before, During, and After Pinochet." En The Road from Mont Pèlerin: The Making of the Neoliberal Thought Collective, editado por Philip Mirowski \& Dieter Plehw, 305-46. Boston: Harvard University Press.

Fontaine, Arturo. 1991. "El miedo y otros escritos: El pensamiento de Jaime Guzmán E.” Estudios Públicos 42: 251-570. 
Friedman, Milton. 1962. Capitalism and Freedom. Chicago: University of Chicago Press.

— 1976a. "The Line We Dare Not Cross." Encounter November: 8-14.

- 1976b. "The Fragility of Freedom." En Milton Friedman in South Africa, editado por Meyer Feldberg, Kate Jowell \& Stephen Mulholland, 3-10. Cape Town: Graduate School of Business, University of Cape Town.

—. 1977. "The Path We Dare Not Take.” Reader's Digest March: 110-15.

Friedman, Milton \& Rose D. Friedman. 1980. Free to Choose: A Personal Statement. Nueva York y Londres: Harcourt Brace Jovanovich.

_ 1998. Two Lucky People: Memoirs. Chicago: University of Chicago Press.

Friedman, Milton, José Piñera, Sergio de Castro, Axel Kaiser \& Jaime Bellolio. 2012. Un Legado de Libertad. Milton Friedman en Chile. Editado por Ángel Soto. Santiago de Chile: Fundación para el Progreso y otros.

Ginzburg, Tom. 2014. "¿Fruto de la parra envenenada? Algunas observaciones comparadas sobre la Constitución chilena." Estudios Públicos 133: 1-36.

Godoy, Óscar. 1999. "La transición chilena a la democracia: Pactada.” Estudios Públicos 74: 79-106.

Góngora, Mario. 1981. Ensayo histórico sobre la noción de Estado en Chile en los siglos XIX Y XX. Santiago, Chile: Ediciones La Ciudad.

Grandin, Greg. 2006. Empire's Workshop: Latin America, the United States, and the Rise of New Imperialism. New York: Henry Holt and Company.

Hammond, J. Daniel. 2003. "Remembering Economics." Journal of the History of Economic Thought 25 (2): 133-43.

Hartwell, Ronald Max. 1995. A History of the Mont Pèlerin Society. Indianapolis: Liberty Fund.

Harvey, David. 2005. A Brief History of Neoliberalism. Oxford: Oxford University Press.

Hayek, Friedrich A., ed. 1935. Collectivist Economic Planning: Critical Studies on the Possibilities of Socialism. London: Routledge.

—_ [1944] 2007. The Road to Serfdom. Chicago: University of Chicago Press.

—. [1945] 2014. "The Use of Knowledge in Society." Reimpreso en The Market and Other Orders, editado por Bruce Caldwell. Chicago: University of Chicago Press.

—_ [1946] 2014. "Individualism: True and False." Reimpreso en The Market and Other Orders, editado por Bruce Caldwell. Chicago: University of Chicago Press.

— [1960] 2011. The Constitution of Liberty. Chicago: University of Chicago Press.

—. [1966] 1967. "The Principles of a Liberal Social Order." En Studies in Philosophy, Politics, and Economics, del mismo autor, 160-77. Chicago: University of Chicago Press. 
- 1973. Rules and Order, Vol. 1 de Law, Legislation and Liberty. Chicago: University of Chicago Press.

- 1973-1979. Law, Legislation and Liberty. Chicago: University of Chicago Press.

- [1973] 1978. "Liberalism". En New Studies in Philosophy, Politics, Economics and the History of Ideas, del mismo autor, 119-51. Chicago: University of Chicago Press.

- [1978] 1999. "The Denationalization of Money." Reimpreso en Good Money, Part II: The Standard, editado por Stephen Kresge, 128-229. Chicago: University of Chicago Press.

—. 1978a. "Dangers to Personal Liberty." The Times, July 11.

- 1978b. "Freedom of Choice." The Times, August 3.

- 1980. "1980's Unemployment and the Unions." Hobart Paper. London: Institute of Economic Affairs.

- 1982. Letter to the Editor. Frankfurter Allgemeine Zeitung, January 6.

-1988. The Fatal Conceit: The Errors of Socialism. Chicago: University of Chicago Press.

Hofmann, Paul. 1977. "Strauss Again Becomes Center of Political Controversy in Bonn." New York Times, November 28, 4.

Huneeus, Carlos. 2007.The Pinochet Regime. Boulder, Colorado: Lynne Rienner Publishers.

Kaldor, Lord Nicholas. 1978. "Chicago Boys in Chile.” The Times, October 18.

Klein, Naomi. 2007. The Shock Doctrine: The Rise of Disaster Capitalism. New York: Henry Holt and Company.

Kresge, Stephen \& Leif Wenar, Eds. 1994. Hayek on Hayek: An Autobiographical Dialogue. London: Routledge.

Letelier, Orlando. 1976. "The 'Chicago Boys' in Chile: Economics 'Freedom's' Awful Toll." The Nation, August 28, 137-42.

Loveman, Brian. 1993. The Constitution of Tyranny. Regimes of Exception in Spanish America. Pittsburgh: University of Pittsburgh Press.

MacEwan, Arthur. 1999. Neo-Liberalism or Democracy? Economic Strategy, Markets, and Alternatives for the 21st Century. London: Zed Books.

Millas, Jorge. 1996. "La concepción de libertad-poder de Friedrich von Hayek." Anuario de Filosofía Jurídica y Social - Sociedad Chilena de Filosofía Jurídica y Social: 449-67.

Mirowski, Philip. 2009. "Postface: Defining Neoliberalism." En The Road from Mont Pèlerin: The Making of the Neoliberal Thought Collective, editado por Philip Mirowski \& Dieter Plehw, 417-55. Boston: Harvard University Press.

Moncada, Belén. 2006. Jaime Guzmán: El político de 1964 a 1980. Santiago de Chile: RIL editores.

Myrdal, Gunnar. 1977. "The Nobel Prize in Economic Science.” Challenge, MarchApril: 50-52. 
Popper, Karl. 1966. The Open Society and Its Enemies. Quinta edición revisada. Princeton: Princeton University Press.

Puryear, Jeffrey M. 1994. Thinking Politics: Intellectuals and Democracy in Chile, 1973-1988. Baltimore: The Johns Hopkins University Press.

Robin, Corey. 2011. The Reactionary Mind: Conservatism from Edmund Burke to Sarah Palin. Oxford: Oxford University Press.

Robin, Corey. 2012. "When Hayek Met Pinochet." Blog del autor: cinco posts. July 18. http://coreyrobin.com/2012/07/18/when-hayek-met-pinochet/

Robin, Corey. 2013. "Nietzsche's Marginal Children: On Friedrich Hayek." The Nation, May 27. http://www.thenation.com/article/174219/nietzschesmarginal-children-friedrich-hayek

Schuessler, Jennifer. 2010. "Hayek: The Back Story." New York Times Sunday Book Review. July 9.

Schumpeter, Joseph. 1946. "Review: F. A. Hayek, The Road to Serfdom." Journal of Political Economy 54 (June): 269-70.

Shearmur, Jeremy. Por publicarse. "The Devil's Disciple? Friedrich Hayek and Carl Schmitt." Australasian Journal of Political Science.

Sierra, Lucas \& Lucas MacClure. 2011. Frente a las mayorias: Leyes supramayoritarias y Tribunal Constitucional en Chile. Santiago de Chile: Centro de Estudios Públicos.

Silk, Leonard. 1977. "Nobel Award in Economics: Should Prize Be Abolished?" New York Times. May 31.

Stedman Jones, Daniel. 2012. Masters of the Universe. Hayek, Friedman, and the Birth of Neoliberal Politics. Princeton: Princeton University Press.

Valdés, Juan Gabriel. 1995. Pinochet's Economists: The Chicago Boys in Chile, Cambridge: Cambridge University Press.

Valenzuela, J. Samuel. 1997. "La Constitución de 1980 y el inicio de la redemocratización en Chile." Working paper 242, Kellogg Institute for International Studies. EP 